\title{
Tectonic evolution of a continental collision zone: A thermomechanical numerical model
}

\author{
G. Toussaint and E. Burov \\ Laboratoire de Tectonique UMR7072, University of Pierre and Marie Curie, Paris, France
}

\section{J.-P. Avouac}

Geological and Planetary Sciences Division, California Institute of Technology, Pasadena, California, USA

Received 3 December 2003; revised 17 August 2004; accepted 15 September 2004; published 30 November 2004.

[1] We model evolution of a continent-continent collision and draw some parallels with the tectonic evolution of the Himalaya. We use a large-scale viscoplasto-elastic thermomechanical model that has a free upper surface, accounts for erosion and deposition and allows for all modes of lithospheric deformation. For quartz/olivine rheology and $60 \mathrm{~mm} / \mathrm{yr}$ convergence rate, the continental subduction is stable, and the model predicts three distinct phases. During the phase $1(120 \mathrm{~km}$ or $6 \%$ of shortening), deformation is characterized by back thrusting around the suture zone. Some amount of delaminated lower crust accumulates at depth. During phase $2(120 \mathrm{~km}-$ $420 \mathrm{~km}$ or $6 \%-22 \%$ of shortening), this crustal root is exhumed (medium- to high-grade rocks) along a newly formed major thrust fault. This stage bears similarities with the period of coeval activity of the Main Central thrust and of the South Tibetan Detachment between 20-16 Myr ago. During phase 3 ( $>420 \mathrm{~km}$ or $22 \%$ of shortening), the crust is scraped off from the mantle lithosphere and is incorporated into large crustal wedge. Deformation is localized around frontal thrust faults. This kinematics should produce only low- to medium-grade exhumation. This stage might be compared with the tectonics that has prevailed in the Himalaya over the last $15 \mathrm{Myr}$ allowing for the formation of the Lesser Himalaya. The experiment is conducted at constant convergence rate, which implies increasing compressive force. Considering that this force is constant in nature, this result may be equivalent to a slowing down of the convergence rate as was observed during the India-Asia collision. INDEX TERMS: 8120 Tectonophysics: Dynamics of lithosphere and mantle - general; 8102 Tectonophysics: Continental contractional orogenic belts; 8159 Tectonophysics: Rheology-crust and lithosphere; 8110 Tectonophysics: Continental tectonics-general (0905); 3210 Mathematical Geophysics: Modeling; KEYWORDS: continental subduction, numerical modeling, Himalaya, rheology, mountain building. Citation: Toussaint, G., E. Burov, and J.-P. Avouac

Copyright 2004 by the American Geophysical Union. 0278-7407/04/2003TC001604\$12.00
(2004), Tectonic evolution of a continental collision zone: A thermomechanical numerical model, Tectonics, 23, TC6003, doi:10.1029/2003TC001604.

\section{Introduction}

[2] Major orogens have resulted from continental collisions that have followed closure of oceanic basins along subduction zones. Such collisions are regarded as key geodynamical processes because of their widespread impact within the converging continents and the potential retroactions on plate tectonics. One of most important case examples refers to the active India-Asia collision that has induced deformation within Eurasia thousands kilometers north of the position of the suture zone [e.g., Molnar and Tapponnier, 1975], and which is believed to have had a major impact on global climate and regional geodynamics [Molnar et al., 1993]. This collision is in particular thought to be responsible for the slow-down of India-Asia convergence rate [Patriat and Achache, 1984], which had been reduced from about $110 \mathrm{~mm} / \mathrm{yr} 50 \mathrm{Myr}$ ago, at the onset of the collision as indicated from stratigraphic evidences [Rowley, 1996], to about $50 \mathrm{~mm} / \mathrm{yr}$ at 30-40 Myr ago. Since then crustal shortening within the Himalayan fold and thrust belt is thought to have absorbed $600-700 \mathrm{~km}$ of Indian lithosphere [e.g., DeCelles et al., 2002]. The tectonic evolution of the Himalaya and southern Tibet that have resulted from this process is sufficiently well constrained [e.g., Searle et al., 1987; Yin et al., 1999; Avouac, 2003] to allow for first order comparisons with physical models. However, at this point, any detailed comparison of numerical experiments and the tectonic evolution of the Himalaya would be premature due to both limited resolution of the numerical models and uncertainties on the geological history of the Himalaya over the last 50 Myr.

[3] The transition from oceanic subduction to continental collision is a complex process that may have several possible scenarios. As it arrives at the trench, the continental crust may simply subduct together with the lithospheric mantle, resulting in positive buoyancy forces opposing tectonic forces that drive the plate. Alternatively, the whole crust, or a part of it, may detach from the lithospheric mantle and remain at surface. Plate convergence then can be absorbed by horizontal shortening, hence thickening by pure shear or folding, of the crust. The lithospheric mantle may (1) keep subducting steadily [e.g., van den Beukel and 
Wortel, 1987], (2) detach (break-off) and sink into the convecting mantle if it is not sufficiently strong to resist buoyancy forces and shear stresses [e.g., Davies and van Blanckenburg, 1995], (3) thicken until it drips into the deeper mantle as a result of a Raleigh-Taylor instability [e.g., Houseman and Molnar, 1997], (4) fold and accommodate shortening by folding [e.g., Burov and Molnar, 1998; Gerbault et al., 1999; Burg and Podladchikov, 2000]. These scenarios may be superimposed in nature and lead to very different geological signatures in terms of tectonometamorphic evolution. Which of these scenarios should prevail, depends on a variety of factors including convergence rate, thickness, rheological and physical composition and thermal structure of continental lithosphere [van den Beukel and Wortel, 1987].

[4] Last but not least, surface processes such as erosion and sedimentation play a key role in orogenic building due their strong participation in orogenic mass balance and due to coupling with isostatic reaction and crustal deformation [Beaumont et al., 1992; Avouac and Burov, 1996]. The significance of the feedback between the surface and tectonic processes for orogenic building was demonstrated in a number of studies [e.g., Beaumont et al., 1992; Kooi and Beaumont, 1994; Avouac and Burov, 1996; Willet, 1999; Burov et al., 2001].

[5] The relative importance of the various tectonic, mantle and surface factors together with the mechanical viability of the proposed scenarios remains largely unclear. These questions can be best addressed through analogue or numerical modeling. In this paper, we address a part of the "collision puzzle" by introducing a new numerical model for Asian type of collision, characterized by rapid convergence of relatively old lithospheres. We then analyze the details of the numerical experiments and draw some parallels with the Himalayan orogen. We also evaluate the effect of the subduction of the buoyant continental lithosphere on the force balance, thickening of the crust, and variations of viscous and frictional resistance to subduction.

[6] Hereinafter we first describe the modeling approach and then the details of the numerical experiments that served the basis for this study. We next point to some particular aspects of the experiments and draw parallels with the India-Asia collision.

\section{Modeling Approach}

[7] Subduction of lithosphere requires that the lower plate remains cold enough to preserve its strength and negative buoyancy as it sinks into the mantle. Otherwise the plate may detach, thicken, fold and/or develop an R-T instability. In the sense of plate tectonics, subduction refers to the state when the plate is being drawn down as a rigid body, that is, the background strain rate and velocity remain constant all along the plate including the slab. This condition can be observed if the slab has no time to warm up due to heat exchange with the hot asthenosphere. The thermal constant $\tau_{t}$ of the surface part of the plate may be high since it primarily depends on plate thickness $d$ and thermal diffusivity $\kappa\left(\tau_{t}=d^{2} / \kappa\right)$. However, the slab is subject to more extensive bilateral heat exchanges with the hot asthenosphere. The efficiency of these heat exchanges depends on the ratio of heat advection rate (=subduction velocity $\left.u_{\mathrm{x}}\right)$ to heat diffusion rate $\kappa /\left(u_{\mathrm{x}} t\right)$. For this reason, the minimal condition for stable subduction can be described, among other parameters, by effective Péclet number:

$$
P e=u_{x}^{2} t / \kappa
$$

where $t$ is a characteristic timescale, $\kappa$ is thermal diffusivity $\left(\approx 10^{-6} \mathrm{~m}^{2} \mathrm{~s}^{-1}\right)$. The corresponding thermal diffusion length is $l_{d}=(t \kappa P e)^{1 / 2}$. For preservation of slab strength, $l_{d}$ should be smaller than $0.5 h_{k} \div h_{k}$, where $h_{k}$ is the minimal thickness of the "elastic" core preserved within the slab. This core is needed to transmit in-plane stresses over large distances without breaking or thickening the lithosphere:

$$
S=P e / P e_{k}>1 \text { where } P e_{k}=u_{x} h_{k} / \kappa
$$

[8] If $S$ is smaller than 1, thermal weakening will prohibit stable subduction process. Observations of lithospheric flexure reveal significant plate strength in zones of oceanic subduction. A typical value of the equivalent elastic thickness (EET) of the oceanic lithosphere, roughly determined by the depth to the $600^{\circ} \mathrm{C}$ geotherm, is $30-50 \mathrm{~km}$ [e.g., Burov and Diament, 1995]. By analogy with oceans, one can suggest that in continents the minimal value of the thickness of the mechanical "core" should be also at least $30-50 \mathrm{~km}$ to enable subduction. Continental plates are characterized by EET values ranging from 15 to $110 \mathrm{~km}$ [e.g., Burov and Diament, 1995; Watts and Burov, 2003]. Consequently, some of them (EET $>30 \mathrm{~km}$ ) can develop oceanic-type subduction provided that other necessary conditions are also satisfied (e.g., the buoyancy versus viscous shear force balance must be positive). For example, consider a convergence rate $u_{x}$ of $1 \mathrm{~cm} / \mathrm{yr}$. Assuming $h_{k}=50 \mathrm{~km}$ we obtain $P e_{k}=15$. For $t$ on the order of a few Myr, $P e$ is smaller than $P e_{k}(S<1)$, suggesting that oceanic type of subduction is improbable for $u_{x} \leq 1 \mathrm{~cm} / \mathrm{yr}$. However, for $u_{x}=5 \mathrm{~cm} / \mathrm{yr}, P e_{k}=75$ and $P e=400(S>5)$ meaning that stable subduction is possible.

[9] One can conclude that continental subduction in a sense is unlikely for convergence rates below $1.5-2.5 \mathrm{~cm} / \mathrm{yr}$, but is not impossible for higher rates. Yet, many additional conditions must be satisfied to allow for continental subduction in nature. In particular, the competing deformation modes, such as RT instability, folding or pure shear should be relatively slow, and the upward drag due to the positively buoyant crust and viscous shear should not negate the downward tectonic and slab pull forces.

[10] The combined effect of these multiple factors has been recently assessed in [Toussaint et al., 2004]. This parametric study has shown that continental subduction can occur and persist over million years if the continental lithosphere is initially cold (temperature at the Moho depth $<550^{\circ} \mathrm{C}$ ), and if the convergence rate is higher than $4 \mathrm{~cm} / \mathrm{yr}$. After the onset of the India-Asia collision, the convergence rate was three times greater than $4 \mathrm{~cm} / \mathrm{yr}$. It is thus 
reasonable to assume that the oceanic subduction could be followed by continental subduction of the cold Indian lithosphere.

\subsection{Numerical Method}

[11] Most early analytical and numerical models of collision orogens were based on kinematics assumptions as to the deformation of the mantle lithosphere and assumed simplified rheology for the continental lithosphere. Following early analytical models based on the theory of plastic (brittle) critical wedge [Chapple, 1978; Davis et al., 1983; Dahlen and Suppe, 1988; Dahlen, 1990], attempts have been made to account for ductile deformation at depth [e.g., Beaumont, 1992; Beaumont et al., 1994; Williams et al., 1994; Chemenda et al., 1995, 1996; Batt and Braun, 1997], as well as for the effect of surface processes [Beaumont, 1992; Avouac and Burov, 1996; Willet, 1999; Beaumont et al., 2001]. Recent dynamic models imply full coupling between mechanical and thermal processes and can be subdivided onto "basal drag" or "S" point models (kinematically constrained mantle part and/or crustal part) [e.g., Beaumont et al., 1994, 2001; Willet, 1999; Vanderhaeghe et al., 2003] and fully dynamic (unconstrained mantle part) models [e.g., Petrini and Podladchikov, 2000; Burov et al., 2001; Pysklywec et al., 2002; Regard et al., 2003; Toussaint et al., 2004]. These models differ also in terms of approximation of rheology and of lithospheric structure. For example, Newtonian viscosity and Drucker-Prager plasticity were used assuming mono-layer lithosphere in [Pysklywec et al., 2002], or multilayer lithosphere in [Beaumont et al., 2001]. Nonlinear viscosity and Mohr-Coulomb plasticity and multilayer crust/lithosphere were used in [Petrini and Podladchikov, 2000; Burov et al., 1999, 2001; Toussaint et al., 2004].

[12] Toussaint et al. [2004] have introduced a thermomechancally coupled explicit visco-plasto-elastic model that accounts for crustal structure and phase changes in the continental lithosphere. Same approach is developed in the present study. We use a finite element (de facto generalized finite difference-finite volume) code Parovoz v7 [Poliakov et al., 1993] that exploits the FLAC algorithm [Cundall, 1989]. This "2.5D" explicit time-marching largestrain Lagrangian code locally solves generalized equations of motion (Newtons's second law) in continuum mechanics approximation (3) and updates them in large strain mode (Jaumann's correction) using constitutive equations (4) that account for explicit elastic-ductile-plastic rheology. The solution of these equations is coupled (using Courant's criterion) with heat transfer equations (5), surface erosion (6) and state equations (7). The algorithm handles strain localization and faulting via explicit nonassociated MohrCoulomb plasticity. It also allows for free surface boundary condition and surface processes (erosion and sedimentation) (4):

$$
\begin{gathered}
\rho \frac{\partial}{\partial t}\left(\frac{\partial \mathbf{u}}{\partial t}\right)-\operatorname{div} \boldsymbol{\sigma}-\rho \mathbf{g}=0 \\
\frac{D \boldsymbol{\sigma}}{D t}=F\left(\boldsymbol{\sigma}, \mathbf{u}, \nabla \frac{\partial \mathbf{u}}{\partial t}, \ldots T \ldots\right)
\end{gathered}
$$

$$
\begin{gathered}
\frac{D T}{D t}=\frac{\partial}{\partial \kappa_{i}}\left(\chi \frac{\partial T}{\partial \kappa_{i}}\right)+\frac{H_{r}}{\rho C_{p}}+\frac{\sigma^{I I} e_{\mathrm{II}}^{d} \times f r a c}{\rho C_{p}} \\
\frac{\partial h}{\partial t}=K_{s} \nabla^{2} h \\
\rho=\rho_{0}\left(1-\alpha\left(T-T_{0}\right)\right)
\end{gathered}
$$

[13] Here $\mathbf{u}, \boldsymbol{\sigma}, \mathbf{g}$ are the respective terms for the displacement, stress, acceleration due body forces. The terms $t, \rho, \kappa, C_{p}, T, H_{\mathrm{r}}$ and $\alpha$ respectively designate the time, density, thermal diffusivity, specific heat, temperature, internal heat production and coefficient of thermal expansion. We use radiogenic decay law for heat production in upper crustal granites $\left(H_{\mathrm{r}}=H_{\mathrm{s}} \exp \left(-h_{\mathrm{r}} / z\right)\right.$, Table 1 [Turcotte and Schubert, 2002]). The terms $\partial / \partial t, D \sigma / D t, F$ denote a time derivative, an objective time derivative and a functional, respectively. The last term in the equation (5) corresponds to shear heating. It includes, respectively, second stress and strain rate invariants and work conversion efficiency multiplier (frac). Because of uncertainty on frac, shear heating was switched off during all experiments. The heat advection is solved together with (3). In equation (6), $h$ is the topography height and $K_{s}$ the coefficient of erosion.

[14] The rheologies, densities and thermal properties of each layer are listed in Table 1. If not stated otherwise, quartz-dominated rheology is assumed for the crust and dry olivine rheology is used for the mantle. The initial thermal distribution is computed from conventional continental geotherms adopted by Burov and Diament [1995] following Parsons and Sclater [1977].

\subsubsection{Explicit Plastic-Elastic-Viscous Rheology}

[15] The numerical method uses explicit elastic-viscousplastic rheology with serially connected elastic, plastic and viscous terms:

$$
e_{i j}^{i}=e_{i j_{-} \mathrm{v}}^{i}+e_{i j_{-} \mathrm{e}}^{i}+e_{i j-\mathrm{p}}^{i},
$$

where $e_{i j}^{i}$ is incremental strain and $v, e, p$ denote viscous, elastic and plastic contribution. In the present study, we used a schema in which $e_{i j}^{i}$ is computed by choosing a rheological couple (visco-elastic or elasto-plastic) that requires minimal stress.

[16] The elastic behavior is described by Hooke's law:

$$
\sigma_{i j}=\lambda \varepsilon_{i i} \delta_{i j}+2 G \varepsilon_{i j}
$$

where $\varepsilon_{i j}$ are components of strain tensor and $\lambda$ and $G$ are Lame's constants. Repeating indexes mean summation and $\delta$ is Kroneker's operator. We use $\lambda=G=30 \mathrm{GPa}$, which is equivalent to commonly inferred values of Young modulus (75 MPa) and Poisson's ratio (0.25) [Turcotte and Schubert, 2002].

[17] The brittle behavior is described by experimental Byerlee's law [Byerlee, 1978]. This law is reproduced by nonassociated Mohr-Coulomb plasticity with zero dilata- 
Table 1. Values of Physical Parameters Used ${ }^{\mathrm{a}}$

\begin{tabular}{|c|c|}
\hline Parameter & Value \\
\hline \multicolumn{2}{|l|}{ All Rocks } \\
\hline Lamé elastic constants $\lambda=G$ & $30 \mathrm{Gpa}$ \\
\hline Friction angle (Mohr-Coulomb criterion) & $30^{\circ}$ \\
\hline Cohesion (Mohr-Coulomb criterion) & $20 \mathrm{MPa}$ \\
\hline \multicolumn{2}{|c|}{$\begin{array}{l}\text { Plastic Properties of Serpentinite } \\
\text { Other Properties as for the Upper Crust) }\end{array}$} \\
\hline$\phi$ friction angle (Mohr-Coulomb criterion) & $5^{\circ}$ \\
\hline$C_{0}$ cohesion (Mohr-Coulomb criterion) & $0 \mathrm{MPa}$ \\
\hline \multicolumn{2}{|c|}{ Specific Upper and Weak (Quartz) Lower Crust Properties } \\
\hline$\rho_{c u}$ (density of the upper crust) & $2800 \mathrm{~kg} \mathrm{~m}^{-3}$ \\
\hline$\rho_{c l}$ (density of the lower crust) & $2900 \mathrm{~kg} \mathrm{~m}^{-3}$ \\
\hline$N$ & 2.4 \\
\hline$A$ & $6.7 \times 10^{-6} \mathrm{MPa}^{-n} \cdot \mathrm{s}^{-}$ \\
\hline$Q$ & $1.56 \times 10^{5} \mathrm{KJ} \cdot \mathrm{mol}^{-1}$ \\
\hline \multicolumn{2}{|c|}{ Specific Strong (Diabase) Lower Crust Properties } \\
\hline$\rho_{c l}$ (density of the lower crust) & $2980 \mathrm{~kg} \mathrm{~m}^{-3}$ \\
\hline & 3.4 \\
\hline$A$ & $2 \times 10^{-4} \mathrm{MPa}^{-n} \cdot \mathrm{s}^{-1}$ \\
\hline$Q$ & $2.6 \times 10^{5} \mathrm{KJ} \cdot \mathrm{mol}^{-1}$ \\
\hline \multicolumn{2}{|c|}{ Specific Eclogite Properties } \\
\hline$\rho_{e}$ (density of eclogite) & $3340 \mathrm{~kg} \mathrm{~m}^{-3}$ \\
\hline & 2.4 \\
\hline$A$ & $6.7 \times 10^{-6} \mathrm{MPa}^{-n} \cdot \mathrm{s}^{-}$ \\
\hline$Q$ & $1.56 \times 10^{5} \mathrm{KJ} \cdot \mathrm{mol}^{-1}$ \\
\hline \multicolumn{2}{|c|}{ Specific Mantle Properties } \\
\hline$\rho_{m}$ (density of lithosphere mantle) & $3330 \mathrm{~kg} \mathrm{~m}^{-3}$ \\
\hline$\rho_{o}$ (density of oceanic slab) & $3350 \mathrm{~kg} \mathrm{~m}^{-3}$ \\
\hline$\rho_{a}$ (density of asthenosphere) & $3310 \mathrm{~kg} \mathrm{~m}^{-3}$ \\
\hline & 3 \\
\hline$A$ & $1 \times 10^{4} \mathrm{MPa}^{-n} \cdot \mathrm{s}^{-1}$ \\
\hline$Q$ & $5.2 \times 10^{5} \mathrm{KJ} \cdot \mathrm{mol}^{-1}$ \\
\hline \multicolumn{2}{|l|}{ Surface Processes } \\
\hline$K_{s}$ (erosion coefficient) & $3000 \mathrm{~m}^{2} \mathrm{y}^{-1}$ \\
\hline \multicolumn{2}{|l|}{ Thermal Model } \\
\hline Surface temperature $(0 \mathrm{~km}$ depth $)$ & $0^{\circ} \mathrm{C}$ \\
\hline Initial temperature at Moho depth $(35-40 \mathrm{~km})$ & $400^{\circ}-500^{\circ} \mathrm{C}$ \\
\hline \multicolumn{2}{|c|}{ Temperature at $250 \mathrm{~km}$ depth (thermal lithosphere) $1330^{\circ} \mathrm{C}$} \\
\hline Temperature at $660 \mathrm{~km}$ depth & $2200^{\circ} \mathrm{C}$ \\
\hline Thermal conductivity (crust) $k_{c}$ & $2.5 \mathrm{Wm}^{-1}{ }^{\circ} \mathrm{C}^{-1}$ \\
\hline Thermal conductivity (mantle) $k_{m}$ & $3.5 \mathrm{Wm}^{-1}{ }^{\circ} \mathrm{C}^{-1}$ \\
\hline Surface heat production $H_{\mathrm{s}}$ & $9.5 \times 10^{-10} \mathrm{~W} \mathrm{~kg}^{-1}$ \\
\hline Radiogenic heat production decay depth $h_{\mathrm{r}}$ & $10 \mathrm{~km}$ \\
\hline & $3.0 \times 10^{-5}{ }^{\circ} \mathrm{C}^{-1}$ \\
\hline Thermotectonic age of the lithosphere $a$ & $450 \mathrm{Ma}$ \\
\hline
\end{tabular}

${ }^{\mathrm{a}}$ Compilation by Burov et al. [2001]. Here $\rho$ is density; $Q, n, A$ are material-dependent parameters of ductile flow laws [Kirby and Kronenberg, 1987; Kohlstedt et al., 1995]. Other parameters from Turcotte and Schubert [2002].

tion angle, friction angle $\phi$ of $30^{\circ}$ and cohesion $C_{0}$ of $20 \mathrm{MPa}$ :

$$
\tau=C_{0}-\tan \phi \sigma_{\mathrm{n}},
$$

where $\tau$ is shear stress, $\sigma_{\mathrm{n}}$ is normal stress $\sigma_{\mathrm{n}}=-(P+$ $\left.\tau^{*} \sin \phi\right)$, where $P$ is the effective pressure ( $P$ is positive here); $\tau^{*}$ is a second invariant of stress such that $\tau^{*^{2}}=$
$1 / 4\left(\sigma_{x x}-\sigma_{y y}\right)^{2}-\sigma_{x y}^{2}$. Condition of transition to brittle failure [Vermeer and de Borst, 1984] is

$$
f=\tau-\left(P \sin \phi+\mathrm{C}_{0} \cos \phi\right)=0 \text { and } \partial f / \partial t=0,
$$

where $f$ is function of failure. In addition, piecewise linear strain softening of cohesion and friction angle are implemented as

$$
\begin{aligned}
& C=C_{0}\left(1-\Upsilon_{\mathrm{c} i} \varepsilon_{\mathrm{pa} i}\right) \\
& \phi=\phi_{0}\left(1-\Upsilon_{\phi i} \varepsilon_{\mathrm{pa} i}\right),
\end{aligned}
$$

where $\varepsilon_{\mathrm{pa} i}$ is accumulated plastic strain and $\Upsilon_{\mathrm{c} i}$ or $\Upsilon_{\phi i}$ are softening coefficients (cohesion and friction, respectively) applied within strain interval $\varepsilon_{\mathrm{pa} i-1}<\varepsilon_{\mathrm{pa} i}<\varepsilon_{\mathrm{pa} i+1} . i$ is number of segment of softening function. We used only weak cohesion softening with $\Upsilon_{\mathrm{c} 1}=0.1$ for $0.01<\varepsilon_{\mathrm{pa} 1}<0.1$ because the "nonassociativity" of Mohr-Coulomb plasticity is sufficient for strain localization.

[18] The ductile behavior is derived from experimental uniaxial creep law:

$$
e_{i j}^{d}=A\left(\sigma_{1}-\sigma_{3}\right)^{\mathrm{n}} \exp \left(-Q R^{-1} T^{-1}\right),
$$

where $e_{i j}^{d}$ is shear strain rate, $A$ is material constant, $n$ is power law exponent, $Q$ is activation enthalpy, $R$ is Boltzman's gas constant, and $T$ is temperature in $\mathrm{K}^{\circ}$.

[19] The instantaneous effective viscosity $\mu_{\mathrm{eff}}$ for this law is defined as:

$$
\tau_{i j} \equiv \mu_{\mathrm{eff}} e_{i j}^{d}
$$

which yields

$$
\mu_{\mathrm{eff}}=e_{i j}^{d(1-\mathrm{n}) / \mathrm{n}} \mathrm{A}^{-1 / \mathrm{n}} \exp \left(Q(n R T)^{-1}\right) .
$$

[20] The uniaxial law (11) is converted to a triaxial form using second invariant of strain rate $e_{\mathrm{II}}^{d}$ and geometrical proportionality factors:

$$
\mu_{\mathrm{eff}}=e_{\mathrm{II}}^{d(1-\mathrm{n}) / \mathrm{n}}\left(\mathrm{A}^{*}\right)^{-1 / \mathrm{n}} \exp \left(Q(n R T)^{-1}\right)
$$

where $e_{\mathrm{II}}^{d}=\left(\operatorname{Inv}_{\mathrm{II}} e_{i j}^{d}\right)^{1 / 2}$ and $\mathrm{A} *=1 / 2 \mathrm{~A} \cdot 3^{(\mathrm{n}+1) / 2}$.

\subsubsection{Local Parameterization of Rheology Laws}

[21] The rheological parameters for flow laws are taken from rock mechanics data (Table 1) [Kirby and Kronenberg, 1987; Kohlstedt et al., 1995]. These data need local parameterization, which can be done from observations of regional isostasy. These observations provide estimates for integrated strength of the lithosphere expressed in terms of long-term rigidity $D$ or EET of the lithosphere. For each of the tested rheological profiles, the predicted EET values were obtained as a function of depth-integrated strength $\left(\int_{\text {depth }} \Delta \sigma d y\right)$ according to the method of [Burov and Diament, 1995] and matched with the observed EET values. The predicted EET values can 


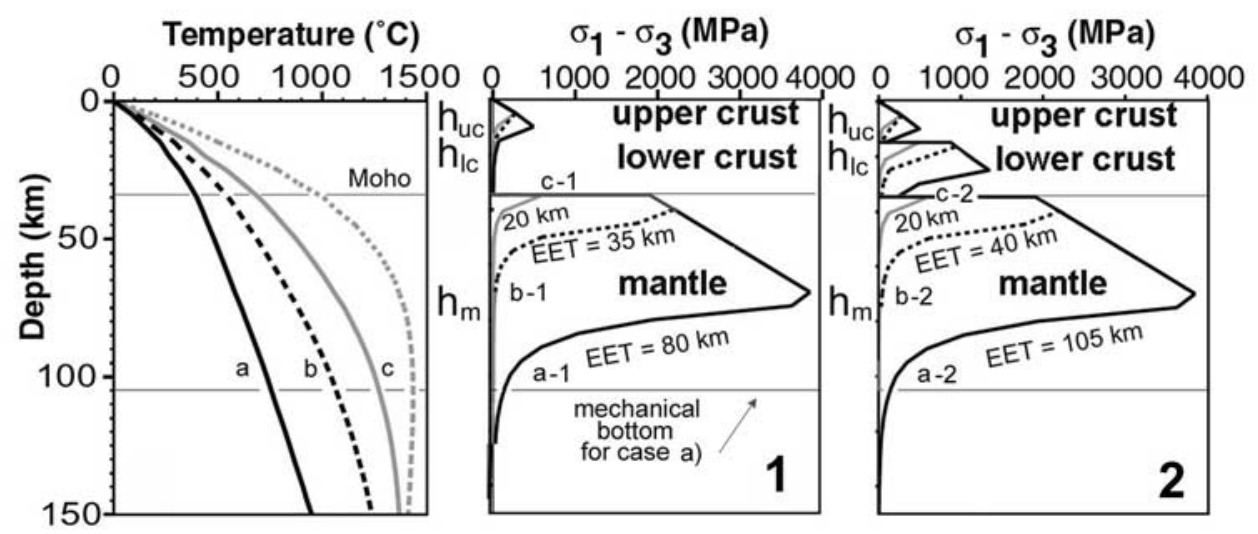

Figure 1. Lithospheric geotherm and associated yield strength envelopes. (middle) Case 1: rheological envelopes for quartz-dominated lower crust. (right) Case 2: rheological envelopes for diabase-dominated lower crust. $h_{\mathrm{uc}}, h_{\mathrm{lc}}$ and $\mathrm{h}_{\mathrm{m}}$ are respective thicknesses of the competent $(\Delta \sigma>10-20 \mathrm{MPa})$ upper crustal, lower crustal, and mantle layers. The geotherm (labeled "a") is representative of Indian lithosphere. EET is predicted equivalent elastic thickness of the lithosphere computed for each rheological profile. The profile that fits best the local EET data is the profile a-1 (see text).

be roughly estimated as [e.g., Burov and Diament, 1995; Watts and Burov, 2003]

$$
\mathrm{EET} \approx\left(h_{\mathrm{uc}}^{3}+h_{\mathrm{lc}}^{3}+h_{\mathrm{m}}^{3}\right)^{1 / 3},
$$

where $h_{\mathrm{uc}}, h_{\mathrm{lc}}$ and $\mathrm{h}_{\mathrm{m}}$ are respective thicknesses of the competent $(\Delta \sigma>10-20 \mathrm{MPa})$ upper crustal, lower crustal and mantle layers (Figure 1). The relation (14) is valid for decoupled layers. In case of coupling, the thicknesses of coupled layers are summed directly. To select the appropriate rheology profile, the rheologically inferred EET values (Figure 1) were matched with the observed EET values $(65-90 \mathrm{~km})$ for Tibet-Hymalaya [e.g., Lyon-Caen and Molnar, 1983; Burov and Diament, 1995; Watts and Burov, 2003]. The rheological profile a-1 (geotherm a, case 1, Figure 1) presents a reasonable choice for the Indian plate, because it both yields EET $\approx 75 \mathrm{~km}\left(h_{\mathrm{uc}} \approx\right.$ $\left.15 \mathrm{~km} ; h_{\mathrm{lc}} \approx 0 \mathrm{~km} ; h_{\mathrm{m}} \approx 70 \mathrm{~km}\right)$ that falls in the middle of the observed range $(65-90 \mathrm{~km})$, and the associated geotherm (a) fits for the Indian lithosphere (thermotectonic age of $450 \mathrm{Ma}$, Moho temperature of $450^{\circ} \mathrm{C}$, surface heat flow $\sim 60 \mathrm{~mW} / \mathrm{m}^{2}$ ). It has been already shown that the flexural support of the Himalaya, as constrained from gravity data, can be correctly predicted from forward modeling assuming rheological properties similar to the profile a-1 [Cattin et al., 2001].

\subsection{Experiment Setup}

\subsubsection{Model Geometry and Structure}

[22] As in most previous studies [e.g., Chemenda et al., 1996], setup geometry of our experiment includes two continental plates at the onset of collision (Figure 2). The oceanic part of the lower plate is entirely subducted, but the continental subduction is not preimposed. Both plates are similar, but the upper plate has a slightly thicker crust $(5 \mathrm{~km}$ thicker) that makes it integrally weaker [Burov and Diament,
1995] and more buoyant than the lower plate. The upper and lower crusts have same rheology parameters but different densities (Table 1).

[23] The model box is large enough $(1900 \times 600 \mathrm{~km}$, or $380 \times 120$ elements) to leave space for all possible modes of deformation including large-scale lithospheric buckling [e.g., Burg and Podladchikov, 2000] and RT instabilities. The grid is made of $5 \mathrm{~km} \times 5 \mathrm{~km}$ quadrilateral elements, each of which consists of four overlapped triangular subelements. This resolution is sufficient to study first order crustal deformation while keeping computation time within reasonable limits. However, although the resolution is higher than in most large-scale subduction models [e.g., Pysklywec et al., 2002], it is not sufficient to reproduce fine features of crustal flow and secondary faults.

\subsubsection{Choice of Rheological Parameters}

[24] As discussed above, the rheological profile was chosen by matching the inferred EET values with locally "observed" isostatic EET values. In case of Tibetan and Indian plates, the observed EET values are $30-40 \mathrm{~km}$ and 65-90 km, respectively [Lyon-Caen and Molnar, 1983; Jin et al., 1994; Burov and Diament, 1995; see also Burov et al., 2001; Watts and Burov, 2003]. The smaller EET values of the Tibetan plateau can be well explained by its doubled crust (70 km thick), which leads to $50 \%$ reduction of EET compared to the Indian plate that has a normal crust (35 km) [Burov and Diament, 1995, 1996; Watts and Burov, 2003]. Consequently, same parameters (Table 1) can be used both for the Tibetan and Indean plates. These parameters are also the same as in [Toussaint et al., 2004]. The geotherm (Figure 1) was varied to make it compatible (geotherm a, Figure 1) with the observed heat flow [Cattin et al., 2001], geotectonic age (400-450 Ma) and with the observed EET values of $75 \mathrm{~km}$ (Figure 1, profile a-1). We use a relatively weak rheology for the lower crust (quartz). According to Toussaint et al. [2004], the use of a stronger (e.g., diabase) rheology enhances crustal subduction, but results in 


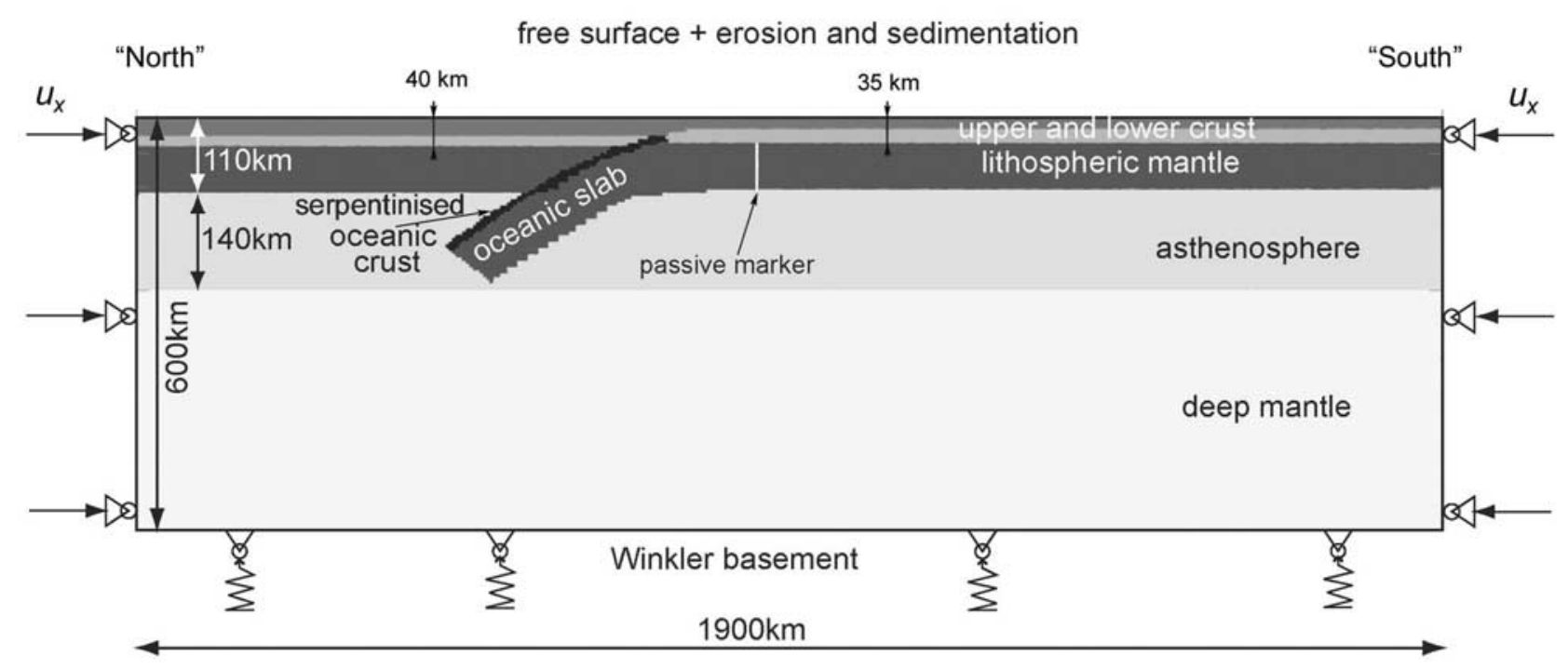

Figure 2. Setup geometry of numerical experiment.

large-scale folding of the lithosphere [see also Burg and Podladchikov, 2000], which is discussible for the Indian plate.

[25] Following Hassani et al. [1997], we introduce a weak interface between the upper and lower plate (serpentinite layer; Table 1). This layer plays a role of a lubrication zone on the initial stages of subduction.

\subsubsection{Boundary Conditions}

[26] One of the open questions concerning the choice of boundary conditions for collision models is whether the "natural" driving boundary conditions should be (1) boundary forces, stresses or velocities and (2) applied at model sides or at the "bottom" of the lithosphere. A number of modeling studies tackle this question by considering that the mode of convergence is known a priori [e.g., Beaumont et al., 2001, 1994; Ellis et al., 1998; Vanderhaeghe et al., 2003], which allows one to apply a kinematic basal drag at crust-mantle or mantleasthenosphere boundary. This otherwise justifiable approach cannot be implemented in our case, because we are interested in crustal and lithospheric dynamics at depth, which requires account for all modes of deformation such as folding and RT instabilities. For this reason, we apply boundary conditions at model sides (constant velocities, total convergence rate of $60 \mathrm{~mm} / \mathrm{yr}$ ) and leave a maximum degree of freedom for deformation inside the model. In nature, the boundary conditions should rather be expressed in terms of constant forces that arise from buoyancy forces along mid oceanic ridges and subduction zones. Given that the configuration of the Indian plate has not changed significantly over the last $50 \mathrm{Myr}$, the force driving indentation of India into Eurasia has probably not varied much [Patriat and Segoufin, 1988]. Yet, implementation of force boundary condition requires continuous readjustment of a priori unknown stress distribution at depth. Instead, to get some idea of forces needed to drive the convergence we apply kinematic lateral boundary conditions and estimate the boundary force from depth integration of boundary stresses.

[27] The upper boundary condition is "free surface" (unconstrained) combined with erosion and sedimentation (equation (6)). For equation (6) we use erosion coefficient $K_{s}$ of $3000 \mathrm{~m}^{2} / \mathrm{y}$, because this value yields denudation rates comparable to those observed in Himalaya, and allows for coupling between surface denudation and the lower crustal flow [Avouac and Burov, 1996].

[28] The bottom boundary condition is a flexible hydrostatic interface (Winkler basement) that imposes free slip in horizontal direction and normal hydrostatic pressure and compensatory stress difference $d \sigma_{n} / d y$ proportional to the vertical deflection of the bottom $\left(d \sigma_{n} / d y=-\Delta \rho g d w / d y\right.$ where $w$ is the vertical deflection and $\Delta \rho$ is the density contrast between the material above and below the bottom).

\subsubsection{Thermal Structure}

[29] Both plates have a thermotectonic age of $450 \mathrm{Ma}$ computed according to Burov and Diament [1995] (Figure 1). This age corresponds to initial Moho temperature of $400^{\circ} \mathrm{C}-500^{\circ} \mathrm{C}(35 \mathrm{~km}$ depth $)$ and yields EET of $65-90 \mathrm{~km}$ for assumed rheology parameters. We also set initial cold thermal anomaly for the imposed oceanic slab using the analytical solution for $150 \mathrm{Myr}$ old oceanic lithosphere subducting at $10-15 \mathrm{~cm} / \mathrm{yr}$ [Turcotte and Schubert, 2002].

\section{A Step by Step Description of the Experiment}

[30] The parametric study by Toussaint et al. [2004] has established parameter ranges (convergence rate, geotherm, crustal thickness, lithological and rheological structure) that determine possible modes of convergence for the first $5 \mathrm{Myr}$ of shortening. This study was based on same numerical 

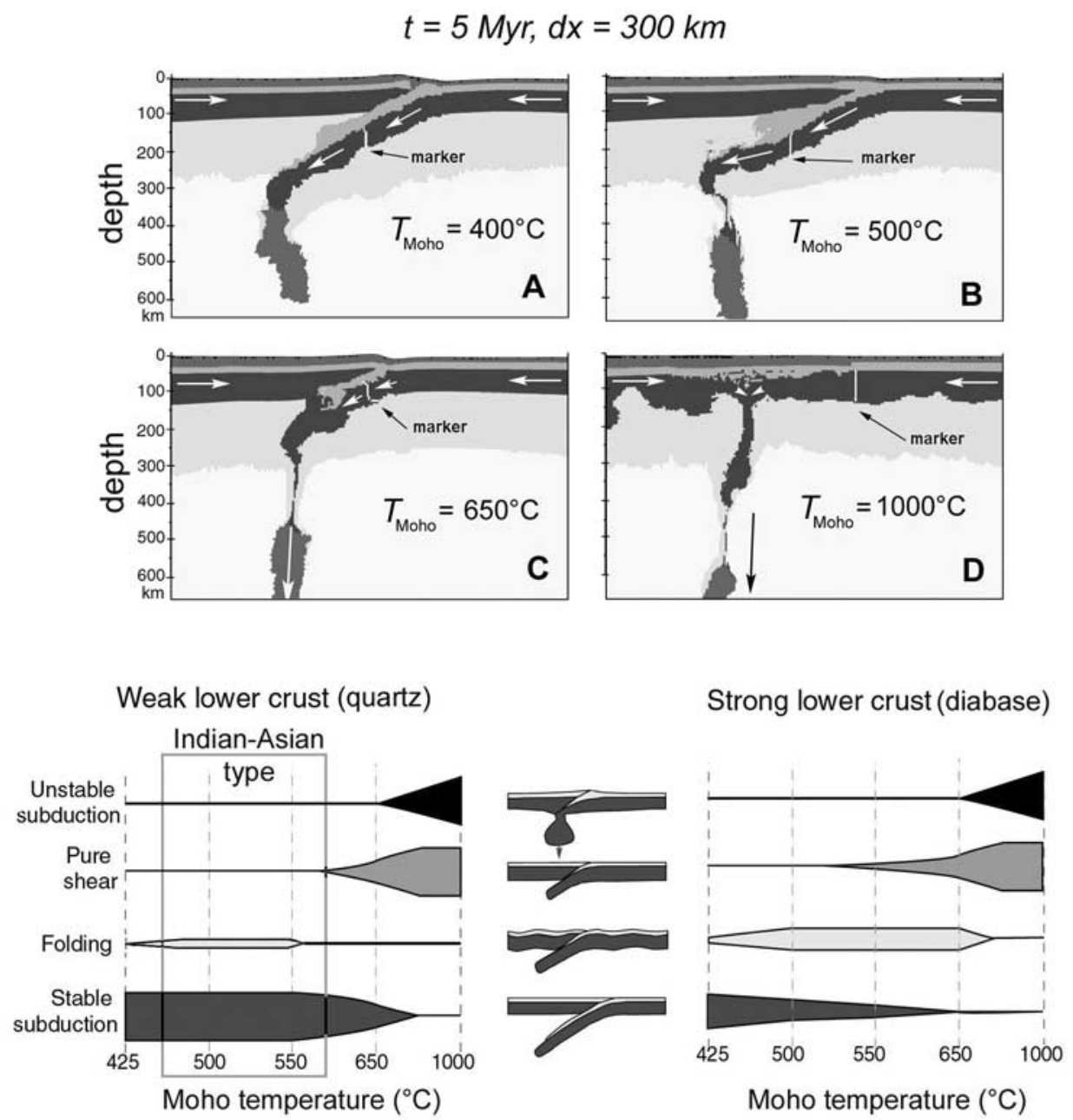

Figure 3. Summary of numerical experiments that explore dependence of collision style (first 5 Myr of collision) on the thermorheological profile for convergence rate of $60 \mathrm{~mm} / \mathrm{yr}$. Rheology parameters are fixed but temperature structure is varied. Because of temperature dependence of the ductile parts of crust and lithosphere, this variation is equivalent to variation of the rheological profile. (top) Evolution of collision zone for $(\mathrm{a}-\mathrm{d})$ four different different geotherms, assuming quartz-dominated rheology for the lower crust. (bottom) Summary of collision modes, as a function of Moho temperature (adopted from Toussant et al. [2004]).

approach, and used a similar initial setup as the present study. This allows us to avoid preliminary tests of model sensitivities and select a parameter range that directly applies to our problem. The Figure 3 shows summary of test experiments for eight different rheology profiles (four different geotherms from "cold" to "hot" for two different lower crustal compositions). As follows from these experiments, the India-Asia collision falls in the parameter range that favors subduction of both continental crust and mantle. We have adopted the best matching experiment (Figure 3, $\mathrm{A}-\mathrm{B})$ to India-Asia collision, and run it for twice larger amount of convergence/subduction $(650 \mathrm{~km})$. This allows us to investigate major phases of evolution of this collision zone that has underwent $500-800 \mathrm{~km}$ of convergence [DeCelles et al., 2001, 2002].
[31] For the setup shown in Figure 2, we first tested model sensitivities to little $(<20 \%)$ variations of thermorheological profile and convergence rate. The results were highly similar in the range of initial Moho temperatures of $400+150^{\circ} \mathrm{C}$ (Figure 3) and convergence rates of $50 \pm$ $10 \mathrm{~mm} / \mathrm{y}$. We then fixed the geotherm $\left(450^{\circ} \mathrm{C}\right.$ at Moho depth) and the total convergence rate $(60 \mathrm{~mm} / \mathrm{y})$. On father stages, the temperature in the subduction channel is affected by subduction rate and by the amount of accumulated heatproducing material. It is noteworthy that since high constant subduction rate was imposed in our experiments, LP/MP-HT metamorphic conditions could not be well reproduced due excessive advection of cold material to the sedimentary prism. In nature, subduction decelerates at postorogenic stage favoring warming of the prism. 
[32] Figures 4-8 and 9 show the evolution of various computed variables such as phase field, strain, strain rate, velocity, apparent viscosity, thermal and stress field. As expected from test experiments shown in Figure 3, the lithospheric mantle subducts all along the experiment. The crustal evolution, however, undergoes remarkable changes, revealing three distinguishable main phases (Figure 9).

\subsection{Phase $1(d x=0-220 \mathrm{~km}$ or $0-12 \%$ of Shortening): Deformation Localized Around the Suture Zone}

[33] During the initial stages of the experiment, the crustal deformation is localized near the suture zone, which we define as the first phase of convergence.

\subsubsection{Subduction of the Lower Crust}

[34] A large part of the lower crust is subducted together with the lithospheric mantle, and by the end of the phase reaches the depth of $100 \mathrm{~km}$ (UHP domain).

\subsubsection{Displacement of the Initial Crustal Suture Zone Toward the Overriding Plate}

[35] A part of the lower crust, and large amount of the upper crust do not subduct, but are "scrapped" off by the upper plate. This results in propagation of the initial suture zone toward the overriding plate. The crust of the upper plate is weak enough to be squeezed horizontally and allows for arrival of new crustal material to the subduction zone. Such displacement of the suture zone has been hinted in the previous numerical experiments of several authors [Sobouti and Arkani-Hamed, 2002; Willet and Beaumont, 1994; Ellis et al., 1998].

\subsubsection{Formation of a Small Primary Lower Crustal Prism}

[36] Instead of subduction, a part of the lower crust is accumulated at surface, forming a small crustal wedge that reaches its maximum size at $d x=220 \mathrm{~km}$.

\subsubsection{The Suture: A Zone of Active Deformation,} Topography, and Exhumation

[37] The suture zone forms a large shear band where the most of crustal brittle and ductile deformation is localized. The deformation pattern indicates a sort of backthrust fault, that roots at the Moho of the upper plate. Some minor deformation also occurs to the "South" (overriding plate, Figures 4-8 and 9), with small thrusts rooting at the Moho of the lower plate. These thrusts have no real influence on the surface topography or velocities. A $5 \mathrm{~km}$ high topography grows in the zone of active deformation. It is associated with high rock uplift velocities $(1 \mathrm{~cm} / \mathrm{yr})$ and high erosion rates $(0.8-1 \mathrm{~cm} / \mathrm{yr})$ yielding residual topography growth rates of $2 \mathrm{~mm} / \mathrm{yr}$. The upward movement of lower crustal elements suggests that some exhumation of crustal depth rocks (HP-HT) occurs in this context. The temperature gradient and effective viscosity field show that the suture zone is also associated with high heat flux, resulting from the upward advection of deep crustal temperatures. Propagation of topography plateward shown in the Figure 9c is similar to results of Beaumont et al. [2001].

\subsubsection{Toward a New Zone of Localization of Crustal} Deformation

[38] At $d x=220 \mathrm{~km}$, the suture zone is no longer the major locus of deformation. The "southern" thrusts are now well developed and start to dominate the surface deformation; new topography grows with growing activity of the thrust faults, resulting in formation of a transient bimodal mountain range: its "northern" summit at the suture zone flattens, while the "southern" summit rises.

\subsection{Phase $2(d x=220-460 \mathrm{~km}$ or $12-25 \%$ of Shortening): Subduction and Exhumation Along the Major Thrust}

[39] From $d x=220 \mathrm{~km}$ to $d x=460 \mathrm{~km}$, a single major thrust fault is active and controls the surface deformation. It is associated with important subduction and exhumation events: the activity of this major thrust fault defines the second phase of convergence. All along this phase, the crustal strain and strain rate patterns are rather simple (Figures 7 and 9) as all deformation is concentrated along this major thrust fault that goes across the whole crust and can be followed deep into the subduction channel. During the activity of this thrust fault, the lateral distribution of horizontal surface velocity exhibits a major change at the point of fault emergence. The lateral distribution of vertical surface velocity indicates rapid rock uplift north of the thrust $(2 \mathrm{~cm} / \mathrm{yr})$ and subsidence south of it. The maximum topography elevation is situated north of the thrust, and experiences very fast erosion (maximum erosion rate of $2 \mathrm{~cm} / \mathrm{yr}$ ). Intense brittle-plastic deformation occurs along this thrust fault, as can been seen on the patterns of the accumulated plastic strain (Figures 7 and 9). No other thrust fault accumulates as much plastic deformation during the phases 1 and 3 .

3.2.1. Phase $2.1(d x=220-300 \mathrm{~km}$ or $12 \%-16 \%$ of Shortening): Thrusting Along the Major Thrust Fault, Dislocation of the Crustal Wedge, and Exhumation 3.2.1.1. A Migrating Thrust

[40] Initially, rooting at the Moho of the lower plate $(d x=$ $220 \mathrm{~km}$ ), the thrust fault then migrates across the subduction channel $(d x=260 \mathrm{~km})$ and settles $(d x=320 \mathrm{~km})$ at the northern boundary (hanging wall) of the subduction channel at the interface between the base of the upper plate (mantle olivine) and the subducted crust (footwall) of the lower plate. 3.2.1.2. Expulsion of the Lower Crustal Prism

[41] Thrusting along this major fault implies a rearrangement of the crustal structure. In particular, the crustal wedge accumulated during the phase 1 is destroyed on phase II. From $d x=220 \mathrm{~km}$ to $d x=300 \mathrm{~km}$, the width of this wedge starts to decrease as it is compressed between the strong lithospheric mantle of the upper and lower plates. The rocks forming the wedge are dragged both upward and bottomward, and the mantle part of the upper plate divides the flow.

\subsubsection{Birth of a Strong Topography}

[42] The topography grows continuously from $d x=$ $220 \mathrm{~km}$ to $d x=320 \mathrm{~km}$, driven by up-thrusting along the major fault and by upward deformation of the wedge material. The maximum surface vertical velocities are about $2 \mathrm{~cm} / \mathrm{yr}$, while erosion rates reach $1.5 \mathrm{~cm} / \mathrm{yr}$.

3.2.1.4. Extensional Deformation and Exhumation at the North of the Thrust

[43] The horizontal velocity (from $d x=260 \mathrm{~km}$ to $320 \mathrm{~km}$ ) manifests small local acceleration corresponding to 
"North"

"South"

0
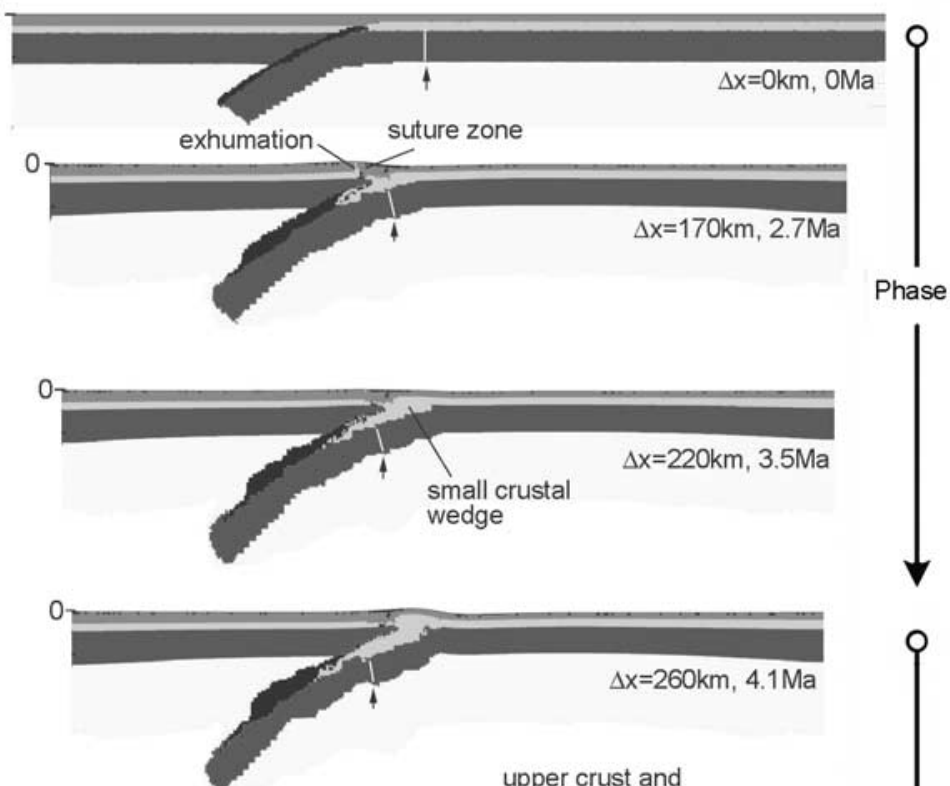

exhumation

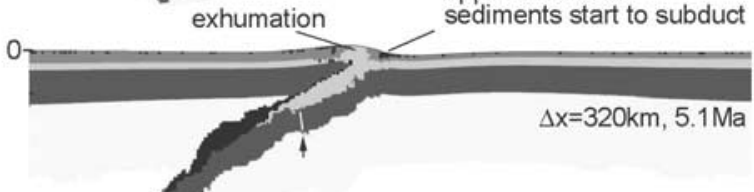

$\Delta \mathrm{x}=260 \mathrm{~km}, 4.1 \mathrm{Ma}$

Phase 1
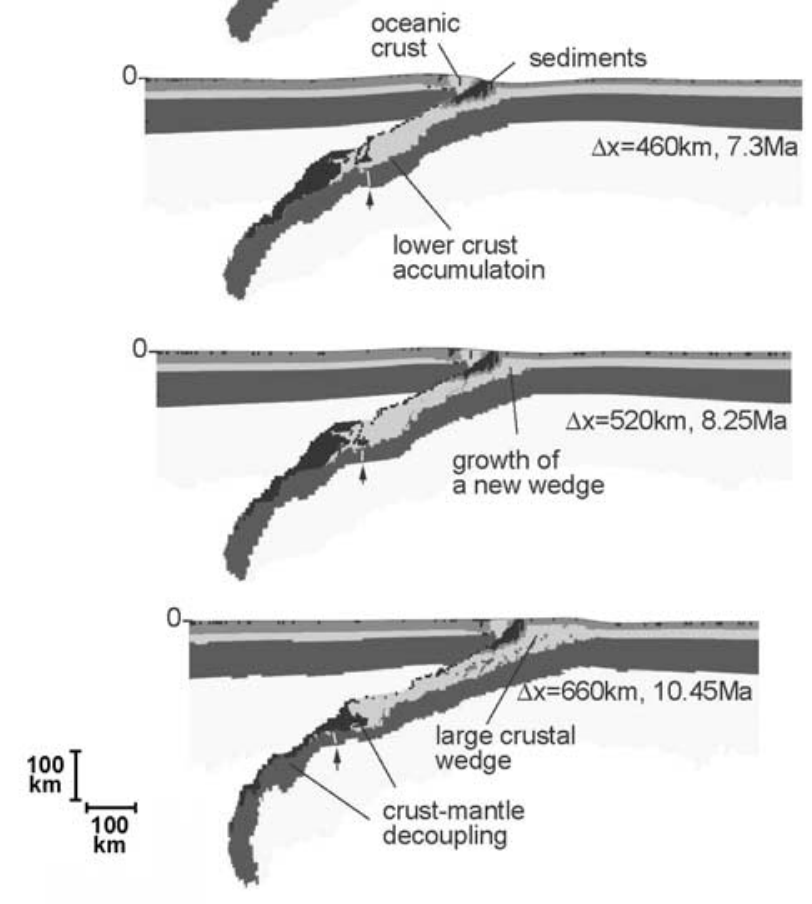

Phase 2

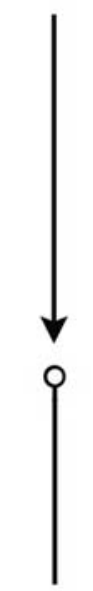

Phase 3

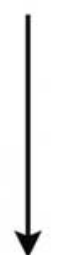

Figure 4. Main experiment on continent-continent collision: evolution of compositional (phase) structure and position of passive marker (vertical black arrow and white strip) that characterizes the degree of subduction. Three subsequent phases of evolution correspond, respectively, to $0-220 \mathrm{~km}$, $220-460 \mathrm{~km}$, and $460-660 \mathrm{~km}$ of shortening. 


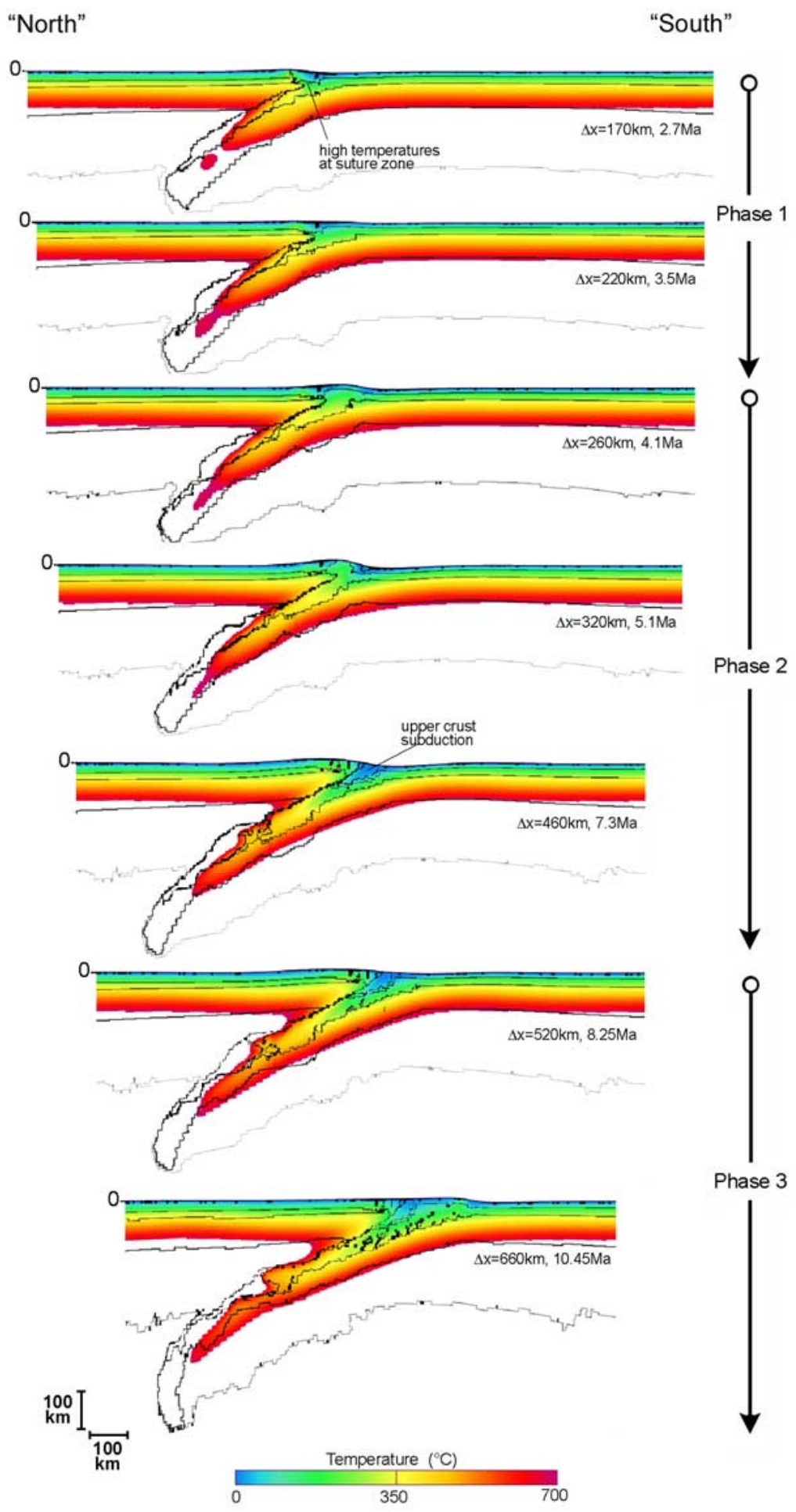

Figure 5. Temperature field for the experiment shown in Figure 4. 


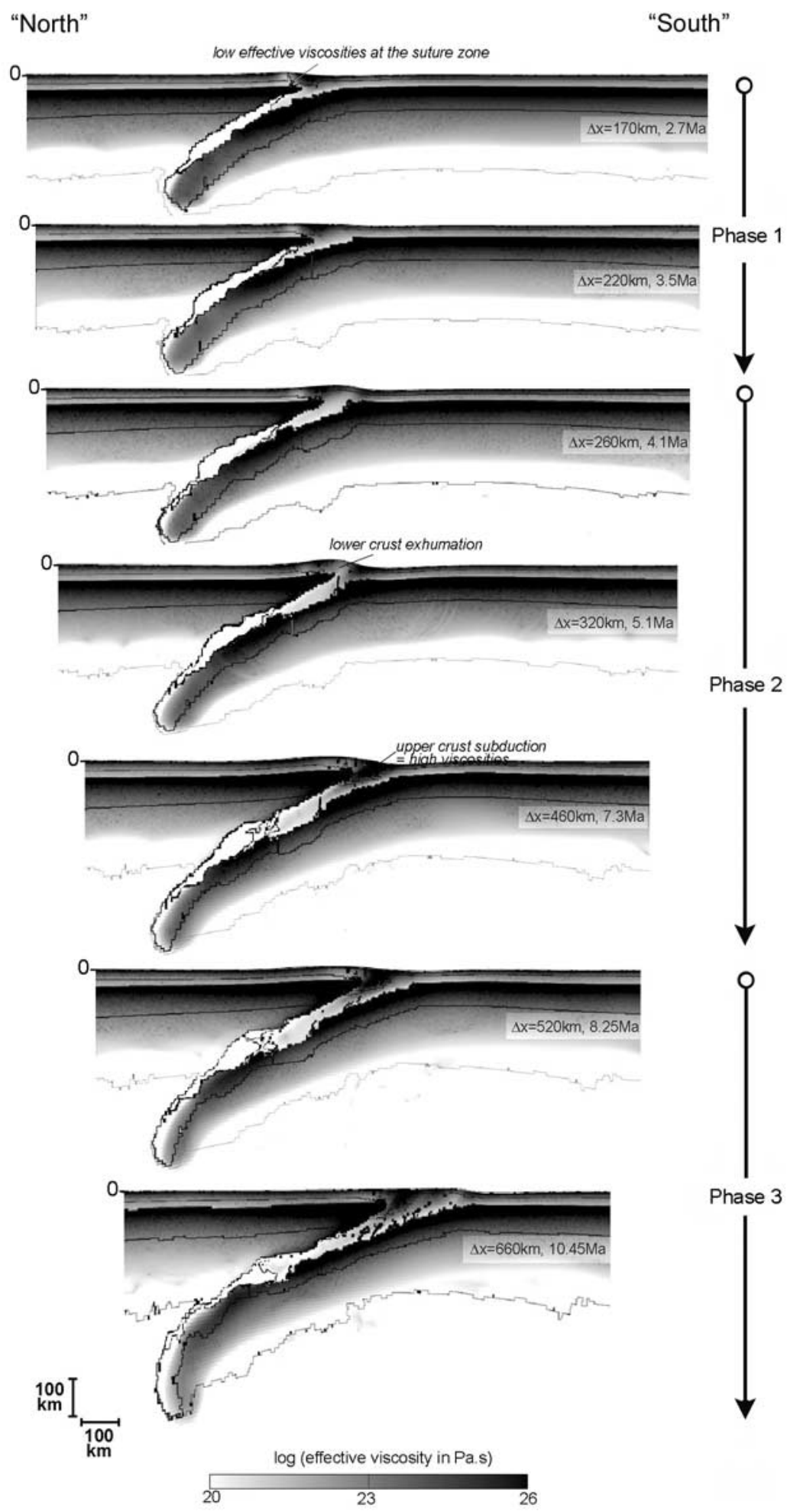

Figure 6. Apparent, or pseudo, viscosity defined as ratio of the effective shear stress to effective strain rate $\left(\mu_{\mathrm{a}}=\tau^{I I} / \dot{\varepsilon}^{I I}\right)$ for the experiment shown in Figure 4 . The apparent viscosity is not used for computations but only for visualization of the results. It is computed for all viscous, elastic and ductile zones (not to be mixed with $\mu_{\text {eff }}$ ). Zones of high pseudo viscosity $\left(>10^{25} \mathrm{~Pa} \mathrm{~s}\right)$ mainly correspond to elastic behavior. 
"North" "South"

0.
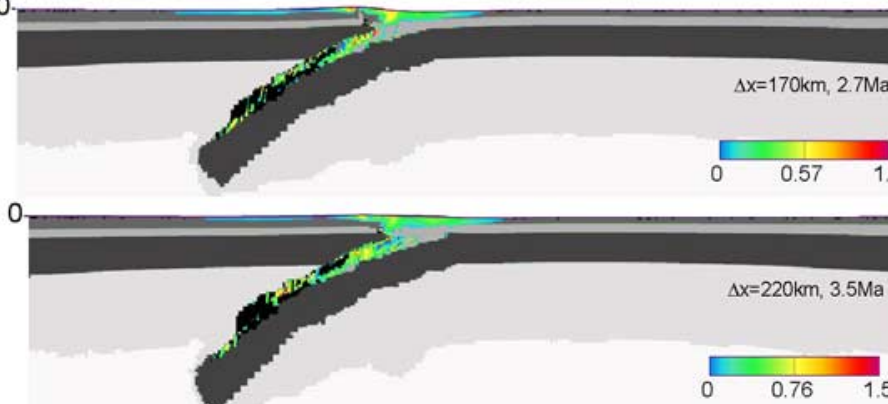

- Phase 1

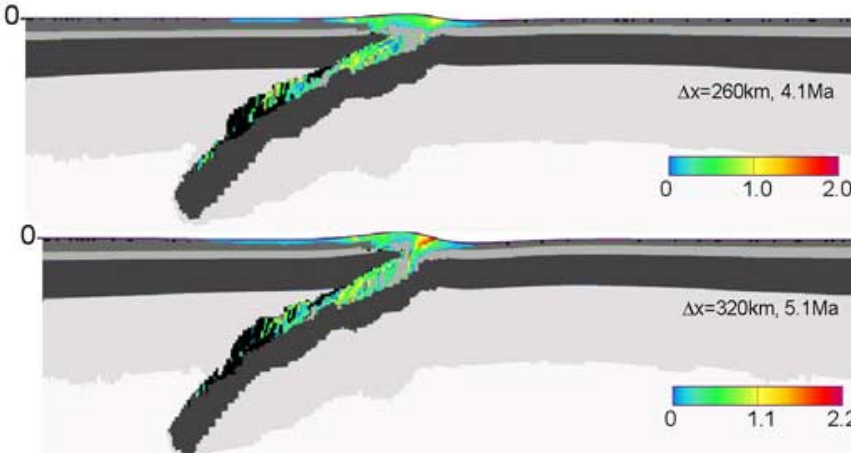

0
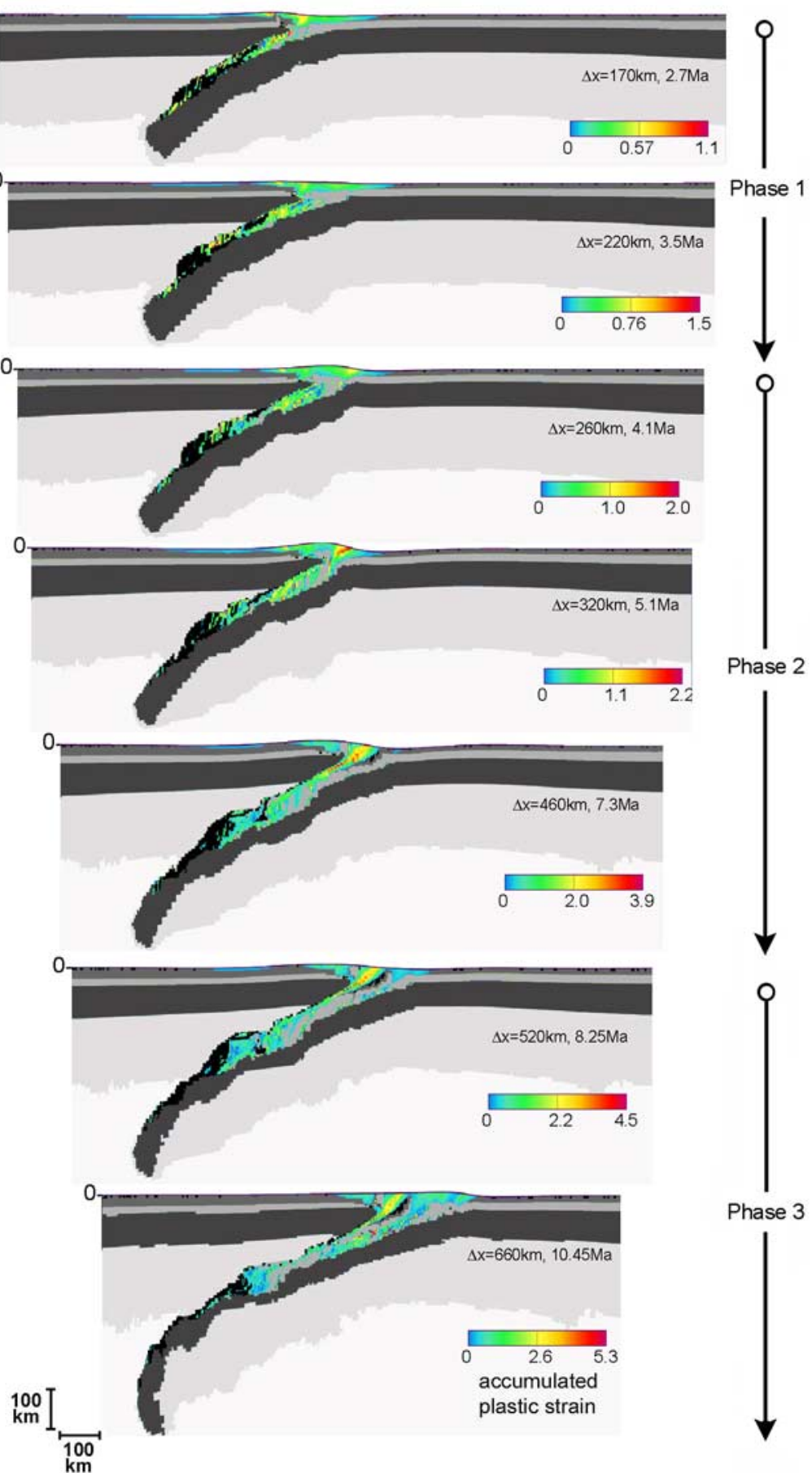

Phase 2

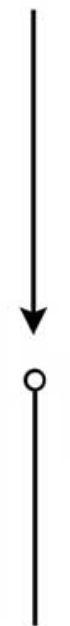

Phase 3

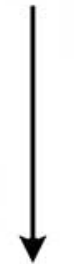

Figure 7. Accumulated plastic strain for the experiment shown in Figure 4.

a zone of crustal extension located at highest topography summits. Exhumation of crustal depth (HP) rocks occurs at $d x=320 \mathrm{~km}$, when the lower crustal material reaches the surface in the zone of extension. The exhumed rocks come from maximum depth of $45 \pm 5 \mathrm{~km}$, which corresponds to the thickness of the dislocated crustal wedge.
3.2.2. Phase $2.2(d x=300-460 \mathrm{~km}$ or $16 \%-25 \%$ of Shortening): Whole Crustal Subduction Along the Major Thrust Fault

3.2.2.1. Subduction of the Upper Crust and Sediments [44] From $d x=320 \mathrm{~km}$ onward, the subduction style undergoes remarkable changes as the upper crust starts to 


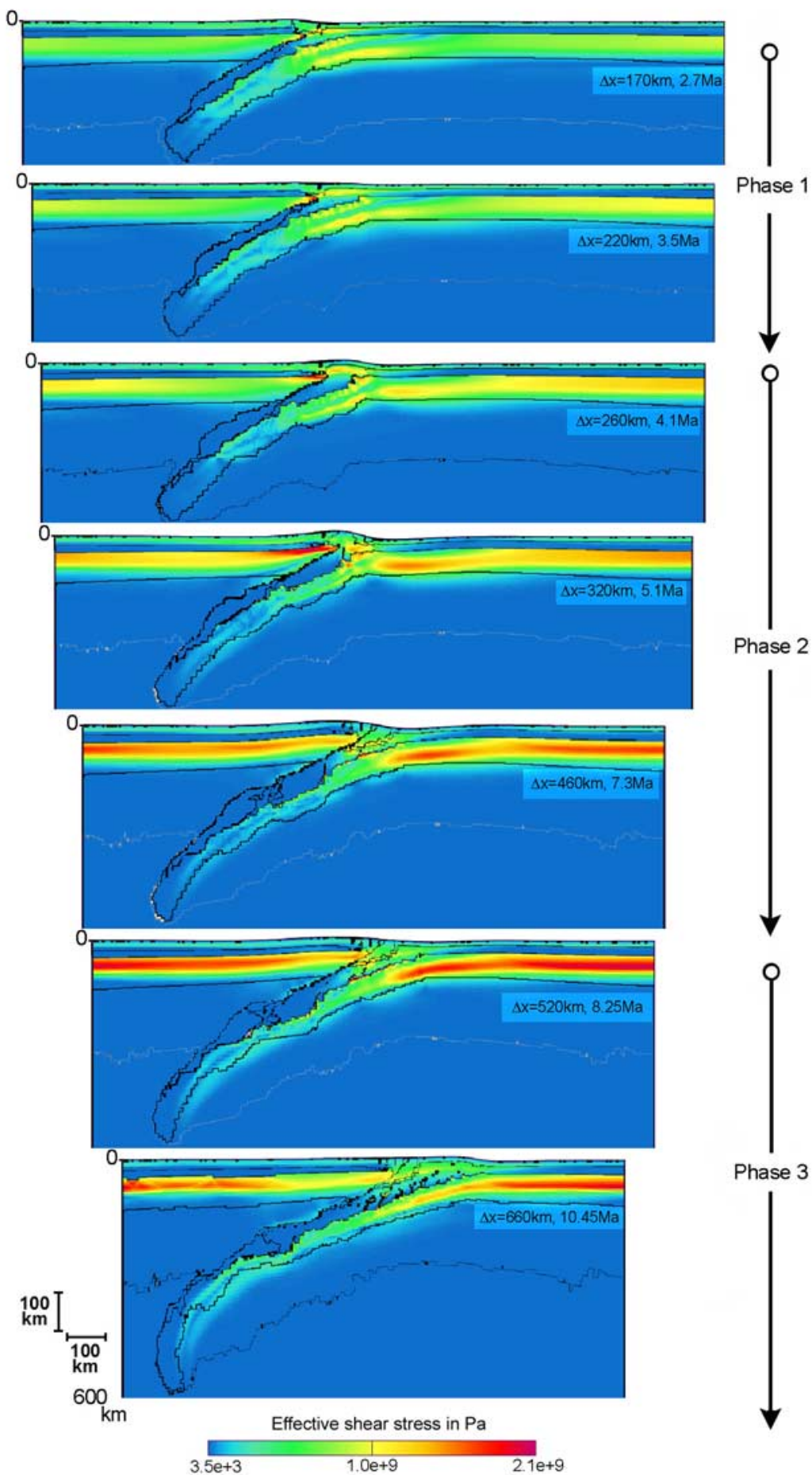

Figure 8. Second stress invariant (effective shear stress) $\sigma_{I I}{ }^{d}=\tau^{I I}$ for the experiment shown in Figure 4. 

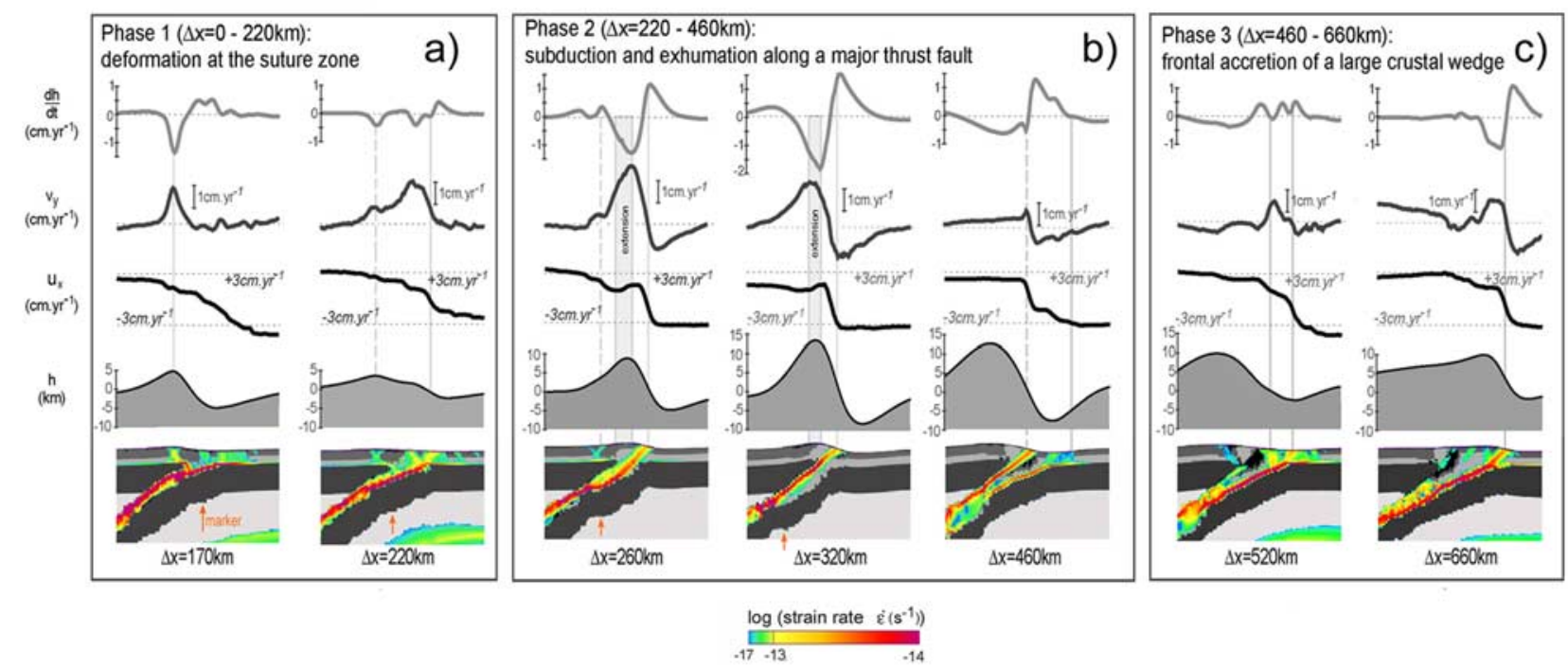

Figure 9. (bottom) Zoom of the effective strain rate in the subduction channel and fault zones $\left(\log _{10} \dot{\varepsilon}^{I I}\right)$ superimposed on contours of phase structure. (top) Topography, $h$, surface horizontal and vertical velocities $\left(u_{\mathrm{x}}, v_{\mathrm{y}}\right)$, denudation and sedimentation rate $\partial h / \partial t$. Gray vertical lines mark key evolution features (position of the suture zone, borders of the main thrust, borders of local extension zones). (a) Phase 1 (0-220 km of shortening). (b) Phase 2 (220-460 km of shortening). (c) Phase 3 (460-660 km of shortening). Note that absolute topography heights are sensitive to erosion law and can be made smaller or larger depending on the assumed coefficient of erosion.

subduct together with the lower crust. At the same time, large amounts of sediments are deposited and subducted with the upper crust. The sedimentation rates reach $2 \mathrm{~cm} / \mathrm{yr}$. Subduction of the upper crust lasts until $d x=460 \mathrm{~km}$, and the maximal crustal burial depth $(75 \pm 5 \mathrm{~km})$.

\subsubsection{A High But Retreating and Widening} Topography

[45] From $d x=320 \mathrm{~km}$, the topography stops rising, and keeps a constant maximum elevation until $d x=460 \mathrm{~km}$. The surface vertical velocities $(2 \mathrm{~cm} / \mathrm{yr})$ are still high, but are counterbalanced by erosion rates. A large quantity of eroded material is deposited south of the range, and enters inside the subduction zone. While the maximum elevation is unchanged, important modifications happen in the mountain range, as it widens, and its maximum elevation migrates $50 \mathrm{~km}$ northward. Interestingly, the mechanisms of topography support also seems to change: originally induced by the upward movement of crustal material along the thrust fault, at $d x=460 \mathrm{~km}$, the range appears to be supported by upward bending of the upper plate.

\subsubsection{End of the Major Thrust Fault Activity}

[46] At $d x=460 \mathrm{~km}$, the movement along the thrust fault becomes less important, and the associated vertical velocities vanish. There is no more extension in the upper plate. It is noteworthy that the rocks forming the upper wall of the thrust now kinematically belong to the upper plate, as can be seen from the horizontal velocity patterns. This decay of the major thrust activity is caused by increase of the size of the crustal prism, which results both in (1) increase of the resistance of the upper plate due increasing volume of cold material accumulated in the prism, in (2) attenuation of transition of driving tectonic stresses through the "buffer" created by a large weak prism. To compensate the decay of the major thrust activity, a new zone of localized deformation forms: high strain rates concentrate along subducting Moho of the lower plate, with new thrust faults emerging to the south. These new faults modify the horizontal velocity profile, as they start to accommodate a part of the convergence.

\subsection{Phase $3(d x=460-660 \mathrm{~km}$ or $25 \%-35 \%$ of Shortening): Accretion of a Large Lower Crustal Wedge}

[47] Once the major thrust fault is abandoned, the deformation style changes dramatically, and a succession of short-lived thrusts results in the accretion of a large crustal wedge.

\subsubsection{Progressive Growth of the Prism}

[48] At $d x=520 \mathrm{~km}$, the distribution of surface velocity and erosion - sedimentation rates indicate activation of a new major thrust, as well as of a less important conjugate thrust fault. The topography cannot be adjusted instantaneously to this new deformation pattern, and at $d x=520 \mathrm{~km}$, the maximum elevations are still situated above the upper plate, some $200 \mathrm{~km}$ to the North of the active thrust fault. At close look, we notice the emergence of a new topography associated with the new thrust faults. The thrust fault that appears at $d x=520 \mathrm{~km}$ is short-lived, and is progressively replaced by another similar thrust fault that forms to the south of the range. This mechanism repeats resulting in a $75 \mathrm{~km}$ lateral migration of the deformation front between $d x=520 \mathrm{~km}$ and $d x=660 \mathrm{~km}$. Some perturbations in the 


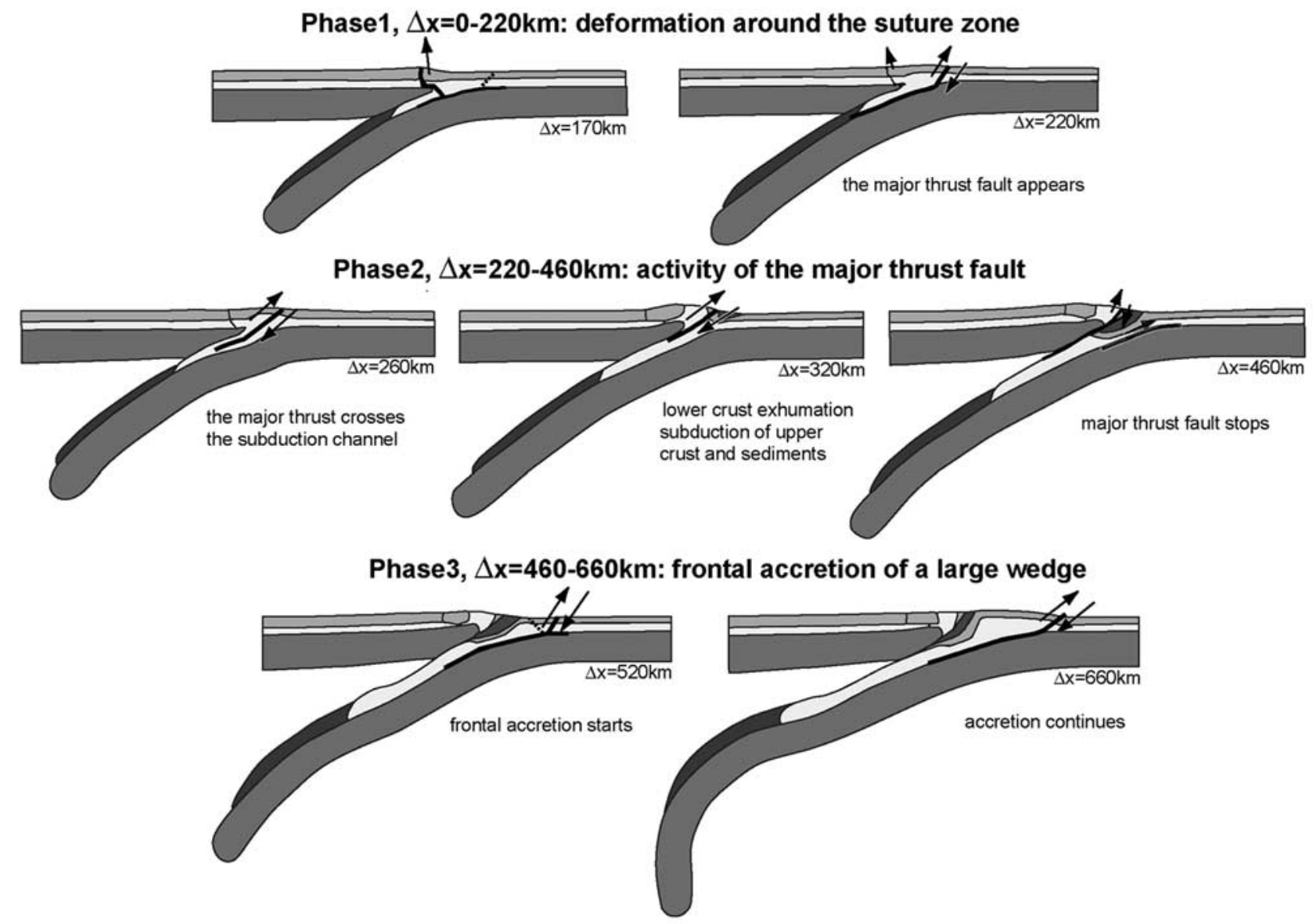

Figure 10. Summary of structural evolution predictedby collision model shown in Figures 4-8 and 9 .

temperature and effective viscosity field occur due to the thrusting movements, but they have moderate amplitudes. Short lived thrusting results in accumulation of crustal material into a large crustal wedge. The topography progressively grows above the prism, while the northern summits are eroded.

\subsubsection{Mature Prism: An Asymmetric Range}

[49] At $d x=660 \mathrm{~km}$, a sort of equilibrium state is reached, and the topography is now supported by the growing wedge. The mountain range remains strongly asymmetric. Its southern side is very steep whereas the surface elevations decrease very slowly northward. The maximum elevation is about $8 \mathrm{~km}$. The range experiences rather high vertical velocities and erosion rates $(1 \mathrm{~cm} / \mathrm{yr})$, but their intensity remains small compared to the phase 2 . We stopped the experiment at $d x=$ $660 \mathrm{~km}$, because the slab has reached the interface between the upper and lower mantle.

\section{Predicted Mantle and Crustal Evolution During Collision}

\subsection{Evolution of the Lithospheric Mantle}

[50] Figure 10 provides an interpretative sketch of the structural evolution during the entire experiment. The lith- ospheric mantle exhibits a strong ability to subduction all along the experiment. After $660 \mathrm{~km}$ of convergence, the total amount of internal horizontal shortening in the mantle lithosphere is negligible (about $20 \mathrm{~km}$ ), so we can consider that the convergence of the mantle lithospheres is entirely accommodated by subduction.

[51] The evolution of the lithospheric mantle is characterized by the absence of dramatic events: the continental slab remains cold and preserves high viscosity at depth (Figures 5 and 6), which prevents slab detachment. The dip angle of the slab strongly increases with depth during the third phase of the experiment, but this is likely to be influenced by the vicinity of the "northern" border of the model. Apart from that, the continental slab has mostly flexural geometry, with a dip angle of about $30^{\circ}$ at $d x=$ $660 \mathrm{~km}$. The dip angle at large depth is strongly conditioned by rheology and density of the embedding mantle. These properties are not very well constrained thus implying significant possible variations.

\subsection{Maximum Crustal Subduction Depth}

[52] The lower crust subducts easily for the range of parameters adopted in the experiments (Figure 11). Even during the phases of crustal wedge building (Figure 12), a 


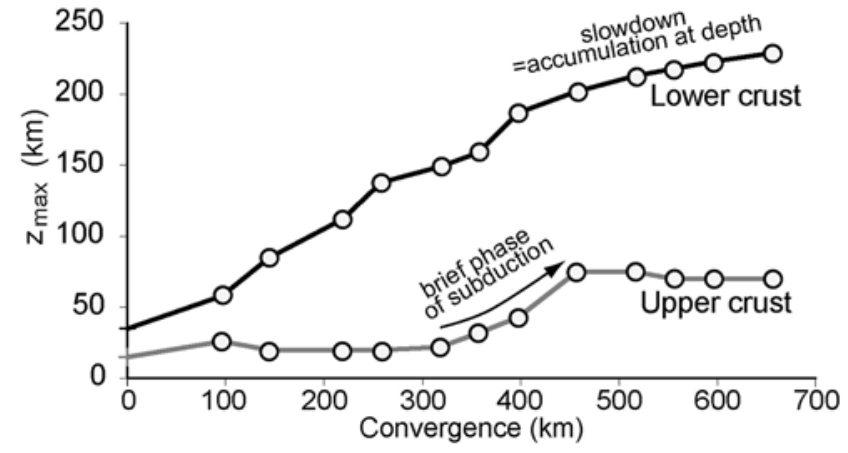

Figure 11. Maximum subduction depths $\left(z_{\max }\right)$ of the upper crust and lower crust as function of the amount of shortening.

part of the lower crust subducts together with the lithospheric mantle. Crustal burial depth increases with time and reaches $225 \mathrm{~km}$ at $d x=660 \mathrm{~km}$. We notice a slowdown in crustal subduction starting from $d x=400 \mathrm{~km}$, when the crust reaches an equilibrium depth of $200 \mathrm{~km}$ (Figure 11). From $d x=400$ to $660 \mathrm{~km}$, the lower crust accumulates at depth of $200 \mathrm{~km}$, and decouples from the advancing lithospheric mantle.

[53] The subduction behavior of the upper crust is quite different from that of the lower crust. As seen from Figures 4-8 and 11, almost all upper crustal subduction occurs between $d x=300 \mathrm{~km}$ to $d x=450 \mathrm{~km}$. The upper crustal material is driven to moderate depths, which do not exceed $75-80 \mathrm{~km}$. Deep subduction of the upper crust is thus unlikely except the cases when the deformation style is specifically favorable (major thrust fault or significantly stronger rheology). The difficulty for subduction of the upper crust results both from its low density and weak rheology, which both favor decoupling between the upper and lower crust. The situation would change if the upper or lower crust were more resistant. However, for boundary and initial conditions of our experiments, such rheology result in overamplified topography or large-scale folding [Toussaint et al., 2004].

\subsection{Dynamics of the Orogenic Wedge}

[54] The crustal wedge dynamics reproduced in the experiments is particularly remarkable, as it displays succession of two main wedges, or prisms (Figure 12). The first wedge is narrow and short lived: it is built and destroyed between $d x=100$ and $d x=300 \mathrm{~km}$. The second wedge is much larger. It is progressively built from $d x=300 \mathrm{~km}$ until the end of the experiment. In detail, this second wedge is composed of two distinct parts: the narrow upper crustal wedge formed during the main thrust fault phase, and the wide lower crustal wedge formed by frontal accretion. The upper crustal wedge is characterized by a cold thermal anomaly, because the advection of surface isotherms is very efficient during the phase of upper crustal subduction. As a result, it remains a high viscosity or brittle zone. On the contrary, the thermal structure of the lower crustal wedge is warmer, and its effective viscosity is lower. It is noteworthy, that the cold thermal regime of the wedge is imposed by high shortening rate used in the experiment. In nature, this rate progressively decreases resulting in reduction of local Peclet number of the wedge and thus in its warming from heat producing elements, which concentration is high in the first $10-15 \mathrm{~km}$ of upper crustal material. The real wedge temperatures may be significantly higher than those obtained in the experiment.

\subsection{Predicted Evolution of Topography}

[55] The topography of this experiment is highly dynamic. All along the experiment, surface elevations, width and location are in constant evolution (Figures 13 and 14). A first topography of moderate amplitude results from initial thrusting at the suture zone. It rapidly flattens, while new topography emerges some $100 \mathrm{~km}$ to the south of the suture zone. This second topography grows and reaches high elevations. Once it stops growing, it remains high for a

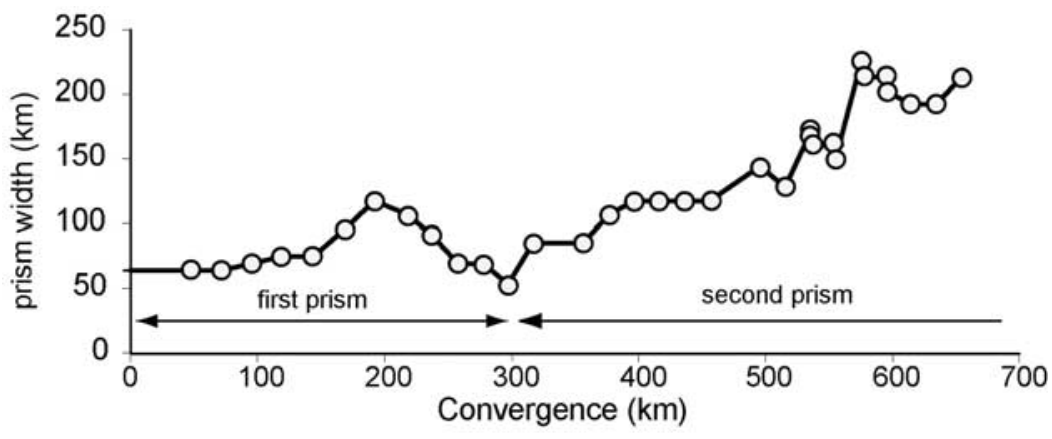

Figure 12. Evolution of the width of the orogenic wedge, as function of the amount of shortening. The vertical axis shows the maximal width of the sedimentary prism at surface (foreland basin), which grows with time until $200 \mathrm{~km}$ of shortening is reached, then it vanishes until $300 \mathrm{~km}$ of shortening is reached. After $300 \mathrm{~km}$ of shortening the prism starts to grow again. The consequent formation of two prisms is related to outward migration of the major thrust fault. 


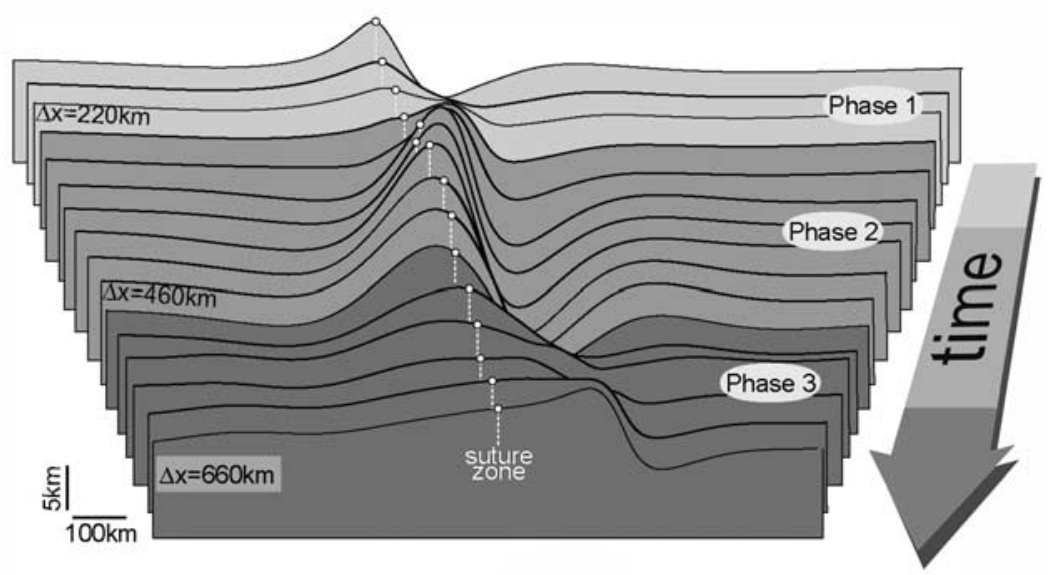

Figure 13. Step by step evolution of surface topography. The vertical gray line indicates the position of the suture zone. Note that absolute topography heights depend on the erosion law $(30 \%-50 \%$ undefiled basins mean that erosion could be faster, which would result in 30\%-50\% smaller topographies. Finetuning of topography was, however, not the primary goal of this study).

long period of time, while it widens and migrates northward. At $d x=420 \mathrm{~km}$, the suture zone is once again found in the area of maximum elevation. Eventually, this topography flattens, while a new, third topography emerges to the South. The third topography progressively grows above the crustal prism, and is characterized by a large width and high asymmetry.

[56] In the model, the maximal topography heights are about $30-50 \%$ larger than in Himalaya. Unnatural topographies are common feature of large-scale dynamic models [e.g., Vanderhaeghe et al., 2003], which stems from the difficulty to account for the properties (erosion, alteration, cohesion etc) of near-surface rocks in a regional model. In our previous Alpine collision model [Burov et al., 2001] the topography amplitudes were correct because of a higher resolution and finer tuning of the erosion law in case of a slowly building range. The diffusion erosion, which mainly accounts for chemical erosion and weathering, is not efficient in case of rapidly growing topographies that are more significantly controlled by gravity driven processes such as hillslope landsliding and stream processes. As result (Figure 13), the resulting topography is too high whereas the basins are underfilled. In Figure 13, the volume of "abnormal" topography is approximately equal to that of missing sediment in the basins, which proves that the abnormal topography is mostly a result of insufficient erosion. In addition, near surface rocks should have lower cohesion $(0-5 \mathrm{MPa})$ than assumed $20 \mathrm{MPa}$, which would result in earlier collapse of exaggerated topography. However, the vertical resolution of the model

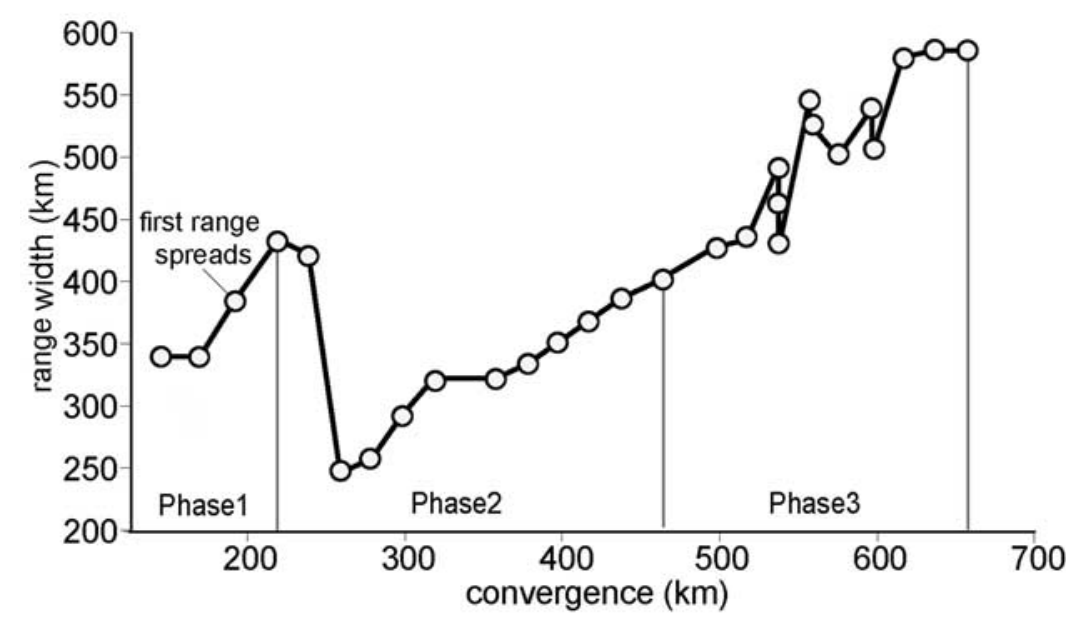

Figure 14. Evolution of the width of the mountain range as a function of the amount of convergence. The consequent formation of two ranges is related to outward migration of the major thrust fault. The vertical axis shows the maximal width of the mountain range. 


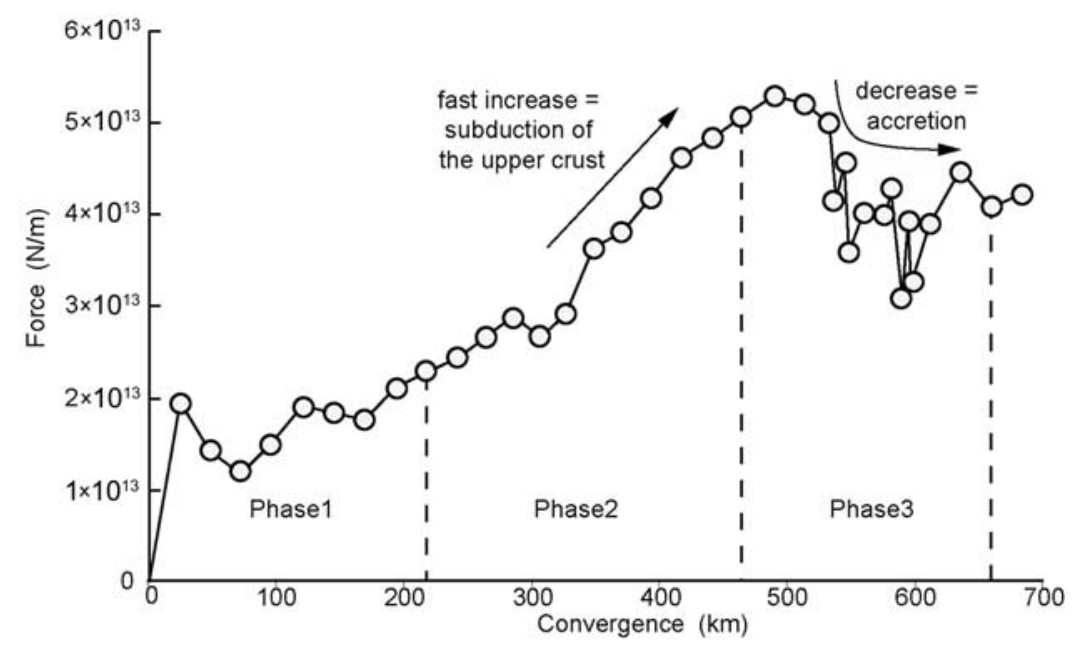

Figure 15. Evolution of the boundary horizontal force (per unit length in out of plane direction) needed to drive the imposed $60 \mathrm{~mm} / \mathrm{yr}$ convergence rate. The three phases of the experiments are marked to facilitate comparison with the tectonic evolution (Figures 9 and 11-14).

does not allow to introduce a special low cohesion surface layer. Tuning to the observed topography was not a goal of this study as it would require introduction of regionally tested erosion/sedimentation laws.

\subsection{Evolution of the Horizontal Force at the Boundary of the Model}

[57] We computed the compressive force necessary to maintain convergence, as integral of deviatoric horizontal stress along the right-hand side of the model (Figure 15). Convergence is more likely to be maintained by constant compressive forces rather than by a constant velocity, the evolution of the compressive force through time is thus one of possible tests of the model viability.

[58] Globally, the force increases with increasing shortening. This suggests that in the real Earth the convergence should slow down when this force is limited. During phase 1 , the force remains relatively low, and only slightly increases. Phase 2 is characterized by a strong increase of the force, especially from $d x=330$, to $d x=480 \mathrm{~km}$, which corresponds to the episode of upper crust subduction. It reaches a maximum value of $5 \times 10^{13} \mathrm{~N} / \mathrm{m}$. When phase 3 begins, the value of the force decreases and then stabilizes around $4 \times 10^{13} \mathrm{~N} / \mathrm{m}$, when the large wedge is accreted. These results suggest that upper crustal subduction is a high energy demanding process. On the contrary, it appears that when the whole crust separates and forms a wedge, subduction of the lithospheric mantle can be maintained at low cost. The reasons for the increase of the boundary force will be discussed in the next section.

\subsection{Metamorphism and Exhumation of Metamorphic Phases}

[59] Two distinct phases of crustal exhumation are reproduced in this experiment. At very early stage, when deformation is localized at the suture zone, we trace exhumation of small quantities of crustal material along the backthrust fault. The exhumed material comes from a maximal depth of $40-45 \mathrm{~km}$, and is exposed to maximum temperatures of $400^{\circ}-450^{\circ} \mathrm{C}$, which correspond to greenshist and blueshist facies observed in the field [e.g., Guillot et al., 1999; DeSigoyer et al., 2000]. Assumption of $50^{\circ}-100^{\circ} \mathrm{C}$ hotter geotherm for the Indian plate (compensated by stronger rheology parameters) would be sufficient to reach lower limits of the eclogite domain. In nature, temperature rise in the accretion prism results from deceleration of subduction rate allowing for more effective heating due to shallow radiogenic sources and heat screening by sediments. These effects are of minor importance for our study since the mechanisms of exhumation are out of its scope. Specifically, we did not trace true $P$ - $t$ depth paths, which would be needed otherwise, because the overpressures $(\rho \mathrm{gz}-P=$ $\left.\rho g z-1 / 3 \Sigma \sigma_{i}\right)$ may (in theory) increase the real pressure $(P=$ $1 / 3 \Sigma \sigma_{i}$ ) in the upper (strong) parts of the crust by a factor of 2 [Petrini and Podladchikov, 2000]. Consequently, the rocks coming from $45 \mathrm{~km}$ depth may correspond to HP and even UHP domain. Our experiments predict high overpressures only in sub-Moho areas outside the subduction channel, although it is not excluded that episodic plate coupling may produce temporary overpressures inside the channel too, for example on the early stages of collision when the channel is not in equilibrium. When subduction is a dominating mechanism of shortening, the zones of HP and UHP overpressure do not overlap with the zones of exhumation. In this case the subduction channel is characterized by near lithostatic pressures or by small underpressures (Figure 16) below the depth of 30-35 km. It is also possible that the predictedoverpressures may be artifacts of application of unconstrained Byerlee's law at depth as well as of kinematic boundary conditions.

[60] The underpressures $(30-50 \%)$ predicted below normal Moho depths (Figure 16) inside the thrust zone and in the uppermost mantle part of the subducting lithosphere are 
a)

$\mathrm{dx}=170 \mathrm{~km}$

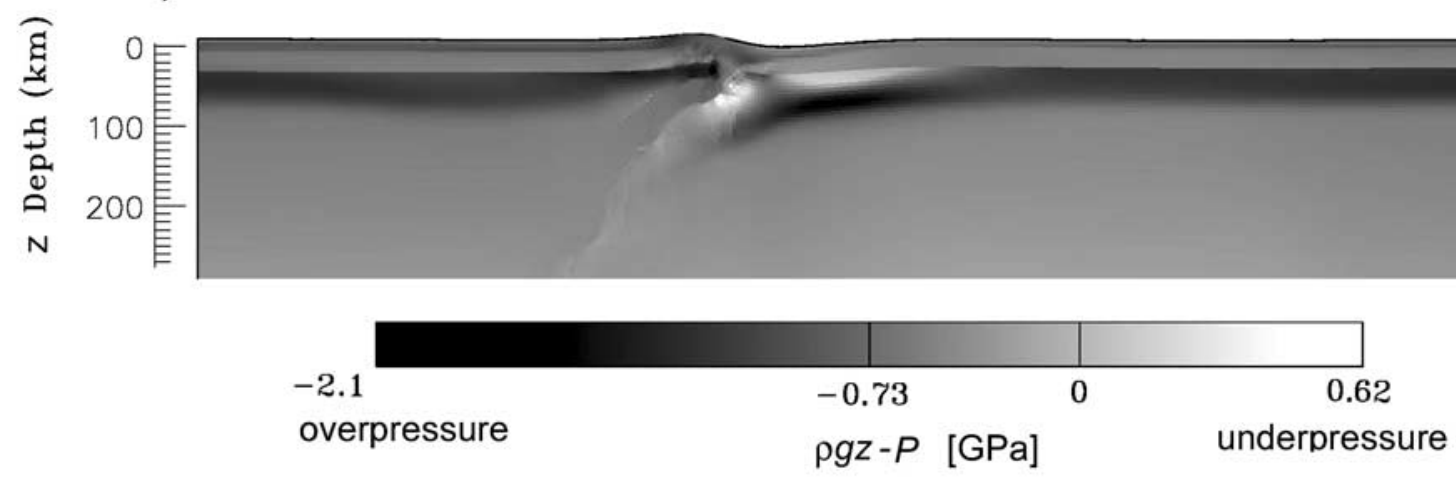

\section{b)}
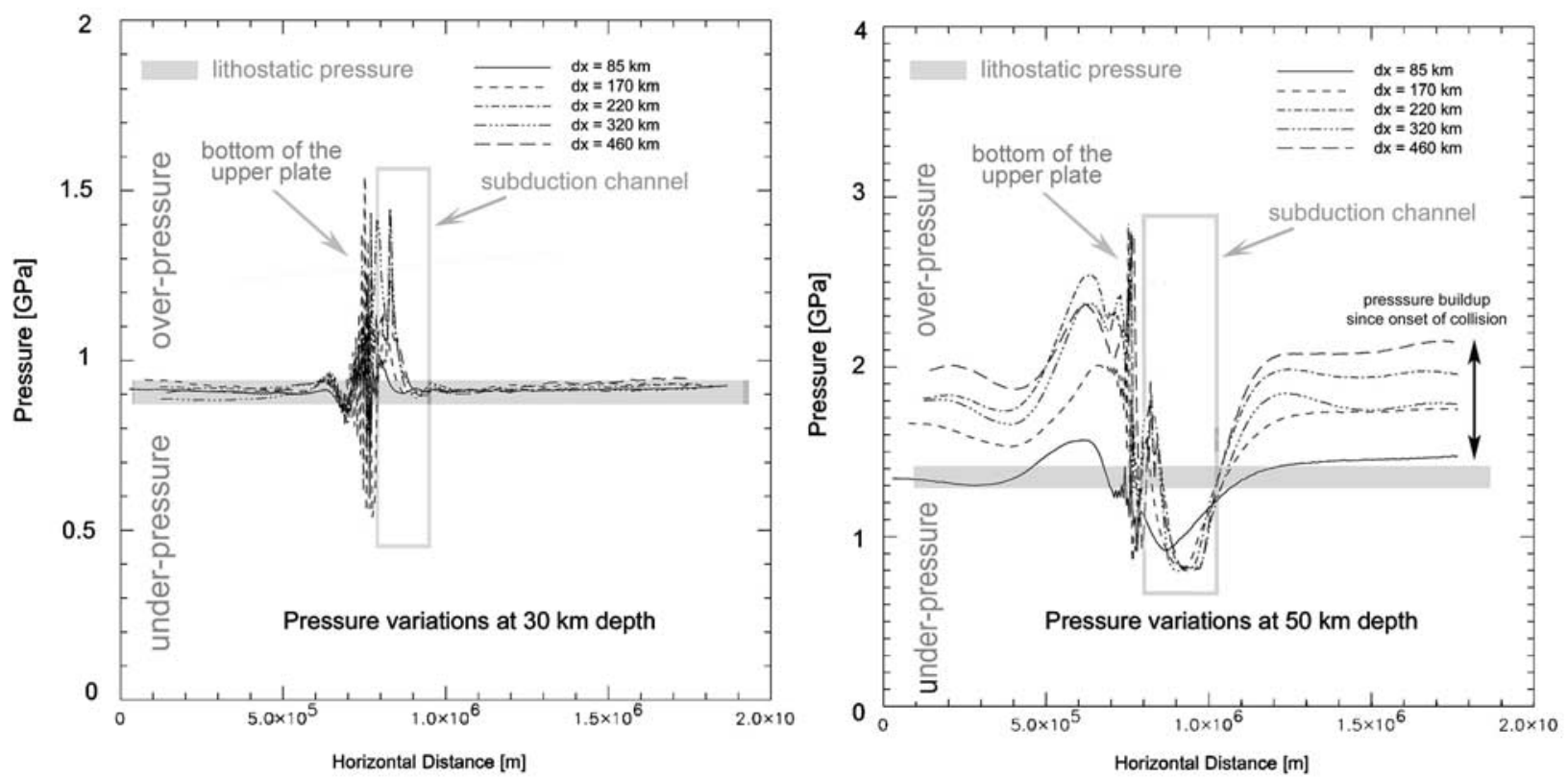

Figure 16. Nonlithostatic pressure distribution for experiment shown in Figures $4-8$ for $d x=170 \mathrm{~km}$. Overpressure is negative and underpressure is positive. (a) Snapshot of nonlithostatic pressure distribution at $d x=170 \mathrm{~km}$. Note that the subduction channel remains nearly lithostatic or is exposed to moderate underpressures produced by flexural tension in the lower plate and low density of the subducting material. The upper wall of the channel is overpressured. (b) Horizontal total pressure profiles at depth of $30 \mathrm{~km}$ (crust) and $50 \mathrm{~km}$ (strong mantle). Overpressure buildup occurs in the upper crustal and mantle layer outside the subduction channel, which, instead, undergoes small underpressures. The values of overpressure may be overestimated becauses of the use of the Byerlee's law and kinematic boundary conditions.

caused by bending stresses and density contrasts. Flexural underpressures are also observed in the lower parts of the upward bending sections of the upper plate. In nature, these zones would pump fluids from the surroundings (i.e., from the subduction channel), whereas the overpressured zones would expulse fluids. The first processes would result in hydration and the second in dehydration. The dehydration of overperessured zones may hinder metamorphic changes whereas hydration of the underpressured zones may facilitate them.

[61] The second phase $(d x=250$ to $320 \mathrm{~km})$ of exhumation involves large rock volumes. It is related to thrusting along the major thrust fault. Both upper and lower crustal rocks are exhumed. They belong to a former part of 
the primary crustal wedge, which is destroyed once the major thrust fault settles. On this stage, the maximal burial depth of the upper crust is $50 \mathrm{~km}\left(450^{\circ} \mathrm{C}+250^{\circ} \mathrm{C}\right)$. The $\left(+250^{\circ} \mathrm{C}\right)$ uncertainty on maximal temperature in the accretion prism comes from the assumption of constant convergence rate, which results in overestimated advection of cold temperature during developed stages of collision. In nature, shortening should be about two times slower at this stage, resulting in four times smaller local Peclet numbers and thus in efficient warming of the prism.

[62] Few elements of the oceanic crust (relics that have escaped subduction at the beginning of the experiment) are dragged by the upward lower crustal flow and are exhumed. As a result, some former oceanic material is found at surface in the middle of the exhumed lower crust.

[63] The experiments do not reproduce exhumation from depths below 75-80 km (UHP-UHT metamorphism). In Himalaya, zones of UHP exhumation are not systematically distributed [e.g., Guillot et al., 1999], which may imply that the mechanism of UHP exhumation was not directly related to the bulk mechanism of collision. As discussed above, UHP rocks may also come from smaller depths than $75 \mathrm{~km}$. In addition to the uncertainties on pressure conditions, temperature-depth relations in crustal channel may differ from inferences of kinematic models commonly used for interpretation of P-T-t data. The volumetric rate of crustal subduction is not constant. The lateral growth of the crustal prism leads to increase of downward advection of cold surface material, resulting in colder geotherms than those that can be expected from kinematic models. Yet, same process may result in overheating of the prism in case of deceleration of subduction, where diffusion of internal heat and heat screening effects take over the heat advection. The predicted "cold" exhumation depths may result from rather cold geotherms assumed in the model. With a $50^{\circ} \mathrm{C}-100^{\circ} \mathrm{C}$ warmer geotherm, the conditions in deepest exhumed material could be close to the HP-HT domain. Deceleration of subduction could also yield an additional local temperature rise (by $100^{\circ}-200^{\circ} \mathrm{C}$ ) in the sedimentary prism resulting in Barrovian type (MP/LP-HT) metamorphism. Finally, the absence of UHP exhumation in the model may also result from the exaggerated topography load that prevents exhumation, or from insufficient numerical resolution that restricts small-scale return movements [Burov et al., 2001].

[64] We did not detect upward movement of deeply buried lower crust from the depths below $90 \mathrm{~km}$ (UHPUHT conditions). It was not the case in our previous model of Alpine collision [Burov et al., 2001]. However, in the Alps, subduction is 5 times slower than in Himalaya, which enhances conductive heating of the subducting material (lower Péclet number). This increases floatability and decreases viscosity of the subducted rock granting its return to the surface. In case of rapid subduction, subducted crust remains cold and strong and is blocked at depth. Nevertheless, upward UHP exhumation can take place even for rapid subduction if the buried crustal material becomes softer due to metamorphic changes, or if subduction is temporarily slowed down. Episodic reduction of subduction rate may occur due to partial plate coupling at the initial stages of transition from the oceanic to continental subduction.

\section{Drawing Parallels With Tectonic Evolution of the Himalaya}

\subsection{Outline of Himalayan Tectonics}

[65] The large amount of shortening $(660 \mathrm{~km})$ in the model allows us to compare it with a large-scale mountain range such as the Himalaya, which has absorbed a similar amount of crustal shortening, though probably not at a constant rate. The Himalayan arc is the major zone of deformation that has absorbed the indentation of India into Eurasia [e.g., Powell and Conaghan, 1973]. The collision started about 50 Myr ago and produced a combination of lateral escape and crustal thickening [Molnar and Tapponnier, 1975]. The convergence rate between India and stable Eurasia then decreased from about $110 \mathrm{~mm} / \mathrm{yr}$ to $50 \mathrm{~mm} / \mathrm{yr}$ within about 10-20 Myr [Patriat and Achache, 1984]. At present, the $4-5 \mathrm{~cm} / \mathrm{yr}$ of northward displacement of India relative to stable Eurasia is still being absorbed by a combination of horizontal shear and crustal shortening.

[66] Relics of the Tethys ocean that used to separate the northern margin of India from the active southern margin of Eurasia now can be traced along the Indus-Tsangpo suture zone (ITSZ) [e.g., Burg, 1983; Searle et al., 1987] well north of the Himalayan summits. To the south, Cambrian to Eocene Tethyan sediments deposited on the northern passive margin of the Indian continent, were sutured to the volcanic and plutonic rocks of the once active margin of Eurasia [Searle et al., 1987; Burg et al., 1987]. Now lying at elevations around $5000 \mathrm{~m}$, they were intensely deformed, probably in the early "Alpine" period of the collision, which lead to the development of the North Himalayan Nappe zone, also called the Tethyan Himalayan thrust belt [e.g., Burg et al., 1984; Yin et al., 1999]. Along the Indus-Tsanpo suture zone, backthrusting seems to be dominant [Ratschbacher et al., 1994]. There is evidence that thrust faulting and crustal thickening in southern Tibet persisted until mid-Miocene times [Yin et al., 1999]. Petrological investigations show that the rocks of North Himalayan Nappe zone underwent a peak metamorphism corresponding to about $22 \mathrm{kbar}$ and $500^{\circ}-600^{\circ} \mathrm{C}$ in western Himalaya [DeSigoyer et al., 2000], and 7-9 Kbar, 500 $550^{\circ} \mathrm{C}$, in central Himalaya [Burg et al., 1987; Guillot et al., 1999].

[67] Extension perpendicular to the range has been documented along a normal fault that separates the Tethyan sedimentary cover from the High Himalayan crystalline units. This fault is called the North Himalayan Normal fault [Burg et al., 1984] or the South Tibetan Detachment [Burchfiel et al., 1992]. Extension is thought to have resumed between about 15 and $20 \mathrm{Myr}$ ago [Searle et al., 1997]. Subsequently, most of the deformation took place south of the STD. The MCT is the major shear zone in the Himalaya. It lies at the front at the high zone where it shows evidence for a combination of brittle and ductile deforma- 
tion. It is estimated to have been active from about 20 to 16 Myr, and it brought to the surface rocks that had temperatures as high as $650^{\circ} \mathrm{C}$ but low pressures of the order of 7-8 kbar (700-800 MPa). Later on, deformation chiefly resulted from thrusting of a number of "colder" thrust faults with a complex imbrication pattern that have formed the Lesser Himalayan thrust fault [DeCelles et al., 2001].

[68] Altogether, crustal shortening across the Himalayan belt, south of the suture zone, is thought to have absorbed a minimum of about $600-700 \mathrm{~km}$ since the onset of the collision [e.g., DeCelles et al., 2002]. At present nearly all of the shortening rate across the Himalaya is absorbed by thrusting along the Main Frontal Thrust fault (MFT)[Lavé and Avouac, 2000]. Structural arguments and geophysical data suggest that all the faults south of the MCT merge into a subhorizontal ductile shear zone at midcrustal depth [Avouac, 2003].

\subsection{Similarities and Dissimilarities With the Model}

[69] The general evolution obtained from the experiments show similarities with the above outlined tectonic evolution of the Himalaya. In both cases, a large crustal wedge developed south of the initial suture zone, and dominant backtrusting is observed along the suture zone.

[70] The first stage of the experiment, with deformation around the suture zone, might be compared to the thrust tectonics described north of the Himalayan range and close to the ITSZ that took place in the early stage of convergence. The major shear zone that forms during stage 2 might be compared with the MCT on which cumulative slip is estimated to be around $200 \mathrm{~km}$. In this experiment slip along the major thrust fault is around $240 \mathrm{~km}$. As we have seen, thrusting is accompanied by normal faulting leading to kinematics close to that derived from the coeval activity of the MCT and the MCT and the STD [DeSigoyer et al., 2000; DeCelles et al., 2001, 2002]. The deformation pattern in the third phase of the model compares well to current tectonics in the Himalaya. In both cases, the only active thrust fault is the most frontal one. In the final stage of the model, the frontal thrust is about $230 \mathrm{~km}$ south of the suture zone, which is comparable to the distance between the MFT and the ITSZ. No deep exhumation process is observed in the model, but small-scale exhumation with at most green schist facies.

[71] Some dissimilarities might also be pointed out. In the Himalaya, it is inferred that the faults south of the MCT root in a mid crustal shear zone. In the model, all the faults root directly at the Moho. This is a direct consequence of the rheological profile that we defined for the lower plate lithosphere: the weaker zone is the lower crust just above the Moho. In order to model a mid crustal shear zone, we could introduce a stiffer lower or intermediate crustal rheology (diabase for instance), which would create an additional decoupling level between the upper and lower crust. Such experiments have been done, but the results are far less comparable with the Himalaya: with a stronger lower crust, subduction involves the whole lithosphere (oceanic type subduction [Toussaint et al., 2004]), and no crustal wedge forms. It is not excluded that better results could be obtained via introduction of an intermediate crustal level with quartz-diorite rheology (which stiffness is between that of the quartz and diabase).

[72] Another limitation of the model is that it does not predict postorogenic LP/MP-HT metamorphism due to the absence of deceleration of shortening rate in the experiments, as well as deep (commonly referred as ultra high pressure) metamorphism discovered along the western Himalayan arc, in particular in the Tso Morari area, and that took place in the very early stage of the collision [DeSigoyer et al., 2000]. The conditions obtained in the numerical model are closer to those described along the central segment of the Himalayan arc. The reasons for the absence of deep $(>75-80 \mathrm{~km})$ exhumation in the model were discussed in the previous sections and, in short, may result from improper shortening rate and initial conditions, or from insufficient numerical resolution. It is also not excluded that the UHP rocks considered as "deep" in reality were formed by overpressures at depths below 75$80 \mathrm{~km}$. The reproduction of metamorphic features stays beyond the scope of this study as it would require detailed data on historic shortening and denudation rates.

\section{Discussion: Some Ideas on Tectonic Forces and Deep Processes in Nature}

\subsection{Increase of the Tectonic Force}

[73] The subduction of buoyant crust, progressive plate bending and viscous shear produce a force resisting to subduction. In case of subduction, this force is negated by far-field and slab pull forces. In our experiments, the magnitude of these forces reaches maximum values of about $5 \times 10^{13} \mathrm{~N} / \mathrm{m}$, which is higher than the ridge push estimated by Richter and McKenzie [1978] and Bott [1991] but of the same order as the slab pull force $\left(2-3 \times 10^{13} \mathrm{~N} / \mathrm{m}\right)$ found by Richter and McKenzie [1978] or the in-plane force derived from stress estimates in the Indo-Australian plate and Indian Ocean [Cloetingh and Wortel, 1985, 1986; Stein et al., 1989]. It may be possible to reach such large forces if stresses tend to focus along the collision zone as can be inferred, for example, from stress distribution within the India-Australia plates or estimated from intraplate stress field [Cloetingh and Wortel, 1985, 1986; Coblentz et al., 1998].

[74] If subduction of the buoyant crust was a major mechanism at the origin of the increase of force in the experiment, the curve of force evolution (Figure 15) would correlate with that of the maximum depth reached by subducted crustal units (Figure 11). Yet, this is only partly the case (Figures 11 and 15). Additional contribution to force growth may come from increasing shear force in the range bounding the thrust fault, amplified by the growing topography load.

[75] Variations in the width and the effective viscosity of the subduction channel may be another reason for variations of the boundary forces. Figures 6,7 , and 8 show that the subduction channel presents a large ductile shear zone during the evolution phases characterized by small increase 
in the boundary force (phases 1 and 3). The transition of horizontal stresses between the colliding plates is attenuated during these phases (plate uncoupling). The boundary force is then conditioned by the resistance of the lithospheric mantle to bending and by shear resistance of deep mantle to subduction. The plate uncoupling also results in reequilibration of pressure in the subduction channel from overlithostatic to near-lithostatic values. When the two plates are decoupled, their strong "elastic" cores are disconnected (Figure 8, shear stress patterns). On the contrary, during the phase 2, when the in-plane force grows, we observe plate coupling expressed in formation of a nearly continuous strong "elastic" core across the whole model (Figures 6 and 8). At this stage, the weak part of the subduction channel is squeezed and gets narrow, allowing for mechanical coupling between the upper and lower plates. On this phase, the collision zone resists to tectonic shortening as a unique plate, and significant nonlithostatic pressure builds up inside the strong mantle parts of the lithosphere.

[76] Rapid subduction results in viscosity increase in the subduction channel, related to the episode of massive subduction of the upper crust and sediments during the growth of the crustal accretion prism; Figure 6 demonstrates that the subducting upper crust has a high viscosity because of rapid advection of cold temperatures from the increasing surface of the crustal prism. In more realistic settings, the upper wall of the subduction channel may be lubricated due the presence of fluids, low-grade metamorphic changes and softening due to shear, which should allow for more efficient subduction of the upper crustal and sedimentary material.

[77] At the end of phase 2, subduction along the major thrust fault becomes difficult, and the evolution of the model reaches a bifurcation point: either subduction continues along a newly formed thrust fault, either it stops and both plates accommodate convergence by folding and pure shear, as is seen from some experiments of Figure 3. The first possibility is favored in the settings of our model, in which at $460 \mathrm{~km}$ of convergence the deformation starts to localize at a thin weak zone above the Moho boundary of the lower plate, and new thrust faults emerge and break through the crust. The new accretion regime is highly favorable to subduction, as the accumulation of lower crust creates a large weak accretion prism. This results in growing Ramberg number (ratio of the gravity forces due weight of the prism to traction forces at its base), which is equivalent to decrease of horizontal force needed for subduction.

\subsection{Driving Forces and the Effect of Eclogitization}

[78] Eclogitization is often referred to as a main driving force for subduction of the continental lithosphere [Austrheim, 1991]. However, the degree of metamorphic changes depends on a number of uncertain factors, such as presence of fluids, which requires a special parametric study. For this reason, although our algorithm handles phase changes, we have neglected the effects of metamorphism. The eclogitisation may have a great influence on the subduction of the upper crust, but, as pointed out by Doin and Henry [2001], it is not an important factor for initiation of subduction in case of cold geotherms, because the crustal rocks remain cold and do not transform into eclogite even at great depth. In our experiments, the temperatures at the base of the subducted upper crust remains slightly below $>500^{\circ}$ $550^{\circ} \mathrm{C}$ necessary for eclogitisation. To test the initial idea the metamorphism has little geodynamic importance in the given context, we have run additional experiments accounting for phase changes (eclogitization at $P=1.5 \mathrm{GPa}$ and $T=$ $500^{\circ} \mathrm{C}$, Table 1). These experiments suggest that the new heavy $\left(\rho_{\mathrm{e}}=3400 \mathrm{~kg} / \mathrm{m}^{3}\right)$ eclogitic phase detaches from the crust and sinks without exerting additional drag on the subducting plate. This happens because the eclogites have a low ductile strength and thus cannot produce important viscous drag. However, the rheology of eclogites is not well constrained, and it is possible that a stronger rheology may have a more important effect on subduction.

\section{Conclusions}

[79] Our study provides a number of new insights into multiphase evolution of lithospheric deformation during a collision orogen, as a result of a combined effect of thermorheological and structural evolution of lithosphere and of surface processes. First of all, the experiments confirm the possibility of long-term continental subduction for central Asia type of collision (rapid convergence of relatively strong plates of different strength). Second, it demonstrates that continental collision may undergo several distinct phases that may entirely originate from internal restructuring, rather than from varying external conditions. In the experiments, a number of parameters, such as the initial crustal thickness or initial thermal structure, have been imposed a priori assuming values corresponding to the central Asian collision. Naturally, these parameters control the results, so that a different parameter set (convergence rate, geotherm, geometry, etc.) applicable to another convergence zone, will result in different predicted evolution of collision zone (Figure 3). We find that our model bears some similarities with "inherently targeted "India-Asia collision, including prediction of three main stages of evolution that correspond to major reorganizations in the kinematics of the crustal deformation. The highly variable topography predicted from our experiments suggests that the topography of the Himalayan range may have been varied significantly during the evolution of the collision. The evolution of the collision zone affects its mechanical properties so that the assumption of a constant convergence rate would require increase of the driving tectonic forces. Since such increase is improbable in nature, one can suggest that the decrease of the convergence rate between India and Eurasia after the onset of the collision may have resulted from combined action of internal mechanisms of tectonic deformation suggested by the numerical experiment.

[80] Acknowledgments. We deeply thank the Associated editor L. Ratschbacher and the reviewers (S. Cloetingh, R. Jamieson, and T. Geria) for constructive comments on the manuscript. We also benefited from discussions with L. Jolivet and L. LePourhiet. Par(o)avoz v7 use engine by A. Poliakov and Y. Podladchikov [Poliakov et al., 1993]. This research was supported in part by the Gordon and Betty Moore Foundation. This is Caltech Tectonic Observatory Contribution 5. This study is not supported by DYETI(INSU-CNRS). 


\section{References}

Austrheim, H. (1991), Eclogite formation and the dynamics of crustal roots under continental collision zones, Terra Nova, 3, 492-499.

Avouac, J. P. (2003), Mountain building, erosion and the seismic cycle in the Nepal Himalaya, Adv. Geophys., 46, 1-80.

Avouac, J. P., and E. B. Burov (1996), Erosion as a driving mechanism of intracontinental mountain growth, J. Geophys. Res., 101, 17,747-17,769.

Batt, G. E., and J. Braun (1997), On the thermomechanical evolution of compressional orogens, Geophys. J. Int., 128, 364-382.

Beaumont, C., P. Fullsack, and J. Hamilton (1992), Erosional control of active compressional orogens, in Thrust Tectonics, edited by K. R. McClay, pp. $1-$ 31, Chapman and Hall, New York.

Beaumont, C., P. Fullsack, and J. Hamilton (1994), Styles of crustal deformation in compressional orogens caused by subduction of the underlying lithosphere, Tectonophysics, 232, 119-132.

Beaumont, C., R. A. Jamieson, M. H. Nguyen, and B. Lee (2001), Himalayan tectonics explained by extrusion of a low-viscosity crustal channel coupled to focused surface denudation, Nature, 414, 738-742.

Bott, M. H. P. (1991), Sublithospheric loading and plate boundary forces, Philos. Trans. R. Soc. London, $337,83-93$.

Burchfiel, B. C., C. Zhiliang, K. V. Hodges, L. Yuping, L. H. Royden, D. Changrong, and X. Jiene (1992), The southern Tibetan detachment system, Himalayan Orogen: Extension contemporaneous with and parallel to shortening in a collisional mountain belt, Spec. Pap. Geol. Soc. Am., 269, 1-41.

Burg, J. P. (1983), Himalayan orogen and global tectonics seen from the Tsangpo suture zone of Tibet (China), in Himalayan Orogen and Global Tectonics, edited by A. K. Sinha, pp. 35-44, Oxford and IBH, New Delhi.

Burg, J.-P., and Y. Podladchikov (2000), From buckling to asymmetric folding of the continental lithosphere: Numerical modelling and application to the Himalayan syntaxes, in Tectonics of the Nanga Parbat Syntaxis and the Western Himalaya, edited by M. A. Khan et al., Geol. Soc. Spec. Publ., 170, $219-236$

Burg, J. P., M. Brunel, D. Gapais, G. M. Chen, and G. H. Liu (1984), Deformation of leucogranites of the crystalline Main Central Sheet in southern Tibet (China), J. Struct. Geol., 6, 532-542.

Burg, J. P., A. Leyreloup, J. Girardeau, and G. M. Chen (1987), Structure and metamorphism of a tectonically thickened continental-crust: The Yalu Tsangpo Suture Zone (Tibet), Philos. Trans. R. Soc. London, Ser. A, 321, 67-86.

Burov, E. B., and M. Diament (1995), The effective elastic thickness $\left(T_{e}\right)$ of continental lithosphere: What does it really mean?, J. Geophys. Res., 100, $3905-3927$

Burov, E. B., and P. Molnar (1998), Gravity anomalies over the Ferghana Valley (central Asia) and intracontinental deformation, J. Geophys. Res., 103, $18,137-18,152$.

Burov, E. B., Y. Podladchikov, G. Grandjean, and J.-P. Burg (1999), Validation of multidisciplinary data using thermo-mechanical modelling: Application to the Western and northern Alps, Terra Nova, 11, $124-131$.

Burov, E., L. Jolivet, L. Le Pourhiert, and A. Poliakov (2001), A thermomechanical model of exhumation of high pressure (HP) and ultra-high pressure (UHP) metamorphic rocks in Alpine-type collision belts, Tectonophysics, 342, 113-136.

Byerlee, J. (1978), Friction of rocks, Pure Appl. Geophys., 116(4-5), 615-626.

Cattin, R., G. Martelet, P. Henry, J. P. Avouac, M. Diament, and T. R. Shakya (2001), Gravity anomalies, crustal structure and thermo-mechanical support of the Himalaya of central Nepal, Geophys. J. Int., 147, 381-392.
Chapple, W. M. (1978), Mechanics of thin-skinned fold-and-thrust belts, Geol. Soc. Am. Bull., 89 $1189-1198$.

Chemenda, A. I., M. Mattauer, J. Malavieille, and A. N. Bokun (1995), A mechanism for syn-collisional deep rock exhumation and associated normal faulting: Results from physical modelling, Earth Planet Sci. Lett., 132, 225-232.

Chemenda, A. I., M. Mattauer, and A. N. Bokun (1996), Continental subduction and a mechanism for exhumation of high pressure metamorphic rocks: New modelling and field data from Oman, Earth Planet. Sci. Lett., 143, 173-182.

Cloetingh, S., and R. Wortel (1985), Regional stress field of the Indian plate, Geophys. Res. Lett., 12, $77-80$.

Cloetingh, S., and R. Wortel (1986), Stress in the IndoAustralian plate, Tectonophysics, 132, 49-67.

Coblentz, D. D., S. H. Zhou, R. R. Hillis, R. M Richardson, and M. Sandiford (1998), Topography, boundary forces, and the Indo-Australian intraplate stress field, J. Geophys. Res., 103, 919-931.

Cundall, P. A. (1989), Numerical experiments on localization in frictional material, Ingenieur Archiv, 59, $148-159$.

Dahlen, F. A. (1990), Critical taper model of fold-andthrust belts and accretionary wedges, Annu. Rev. Earth Planet Sci., 18, 55-99.

Dahlen, F. A., and J. Suppe (1988), Mechanics, growth and erosion of mountain belts, Spec. Pap. Geol. Soc. Am., 218, 161-178.

Davies, J. H., and F. van Blanckenburg (1995), Slab breakoff: A model of lithospheric detachment and its test in the magmatism and deformation of collisional orogens, Earth Planet. Sci. Lett., 129, 85 102

Davis, D., J. Suppe, and F. A. Dahlen (1983), Mechanics of fold-and-thrust belts and accretionary wedges, J. Geophys. Res., 88, 1153-1172.

DeCelles, P. G., D. M. Robinson, J. Quade, T. P. Ojha C. N. Garzione, P. Copeland, and B. N. Upret (2001), Stratigraphy, structure, and tectonic evolution of the Himalayan fold-thrust belt in western Nepal, Tectonics, 20, 487-509.

DeCelles, P. G., D. M. Robinson, and G. Zandt (2002), Implications of shortening in the Himalayan foldthrust belt for uplift of the Tibetan Plateau, Tec tonics, 21(6), 1062, doi:10.1029/2001TC001322.

DeSigoyer, J., V. Chavagnac, J. Blichert-Toft, I. M. Villa, B. Luais, S. Guillot, M. Cosca, and G. Mascle (2000), Dating the Indian continental subduction and collisional thickening in the northwest Hiamalaya: Multichronology of the Tso Morar eclogites, Geology, 28(6), 487-490.

Doin, M.-P., and P. Henry (2001), Subduction initiation and continental crust recycling: The roles of rheology and eclogitization, Tectonophysics, 342, 163-191.

Ellis, S., C. Beaumont, R. A. Jamieson, and G. Quinlan (1998), Continental collision including a weak zone: The vise model and its application to the Newfoundland Appalachians, Can. J. Earth Sci. $35,1323-1346$.

Gerbault, M., E. B. Burov, A. Poliakov, and M. Dagnieres (1999), Do faults trigger folding in the lithosphere? Geophys. Res. Lett., 26, 271-274.

Guillot, S., M. Cosca, and P. Allemand (1999), Contrasted metamorphic and geochronological evolution along the Himalayan belt, in Himalaya and Tibet: Mountain Roots to Mountain Tops, edited by A. Macfarlane, R. B. Sorkhabi, and J. Quade, Spec. Pap. Geol. Soc. Am., 328, 117-128.

Hassani, R., D. Jongmans, and J. Chery (1997), Study of plate deformation and stress in subduction processes using two-dimensional numerical models, J. Geophys. Res., 102, 17,951-17,965.

Houseman, C. A., and P. Molnar (1997), Gravitational (Rayleigh-Taylor) instability of a layer with nonlinear viscosity and convergence thinning of continental lithosphere, Geophys. J. Int., 128, $125-150$.
Jin, Y., M. K. McNutt, and Y. Zhu (1994), Evidence from gravity and topography data for folding in Tibet, Nature, 371, 669-674.

Kirby, S. H., and A. K. Kronenberg (1987), Rheology of the lithosphere: Selected topics, Rev. Geophys., 25, 1219-1244. (Correction, Rev. Geophys., 25, $1680-1681,1987$.

Kohlstedt, D. L., B. Evans, and S. J. Mackwell (1995), Strength of the lithosphere: Constraints imposed by laboratory experiments, J. Geophys. Res., 100, $17,587-17,602$

Kooi, H., and C. Beaumont (1994), Escarpment evolution on high-elevation rifted margins: Insights derived from a surface processes model that combines diffusion, advection and reaction J. Geophys. Res., 99, 12,191-12,210.

Lavé, J., and J.-P. Avouac (2000), Active folding of fluvial terraces across the Siwaliks Hills, Himalayas of central Nepal, J. Geophys. Res., 105, 5735 5770

Lyon-Caen, H., and P. Molnar (1983), Constraints on the structure of the Himalaya from an analysis of gravity anomalies and a flexural model of the lithosphere, J. Geophys. Res., 88, 8171-8191.

Molnar, P., and P. Tapponnier (1975), Cenozoic tectonics of Asia: Effects of a continental collision, Science, 189, 419-426.

Molnar, P., P. England, and J. Martinod (1993), Mantle dynamics, uplift of the Tibetan plateau and the Indian monsoon, Rev. Geophys., 31, 357-396.

Parsons, B., and J. G. Sclater (1977), An analysis of the variation of ocean floor bathymetry and heat flow with age, J. Geophys. Res., 82, 803-827.

Patriat, P., and J. Achache (1984), India-Eurasia collision chronology has implications for crustal shortening and driving mechanism of plates, Nature, $311,615-621$.

Patriat, P., and J. Segoufin (1988), Reconstruction of the central Indian Ocean, Tectonophysics, 155(1-4), $211-234$

Petrini, K., and Y. Podladchikov (2000), Lithospheric pressure-depth relationship in compressive region of thickened crust, J. Metamorph. Geol., 18, 6777

Poliakov, A., Y. Podladchikov, and C. Talbot (1993), Initiation of salt diapirs with frictional overburden: Numerical experiments, Tectonophysics, 228, 199 210.

Powell, C. M., and P. J. Conaghan (1973), Polyphase deformation in phanerozoic rocks of the central Himalayan gneiss, northwest India, J. Geol., 81, $127-143$

Pysklywec, R. N., C. Beaumont, and P. Fullsack (2002), Lithospheric deformation during the early stages of continental collision: Numerical experiments and comparison with South Island, New Zealand, J. Geophys. Res., 107(B7), 2133 doi:10.1029/2001JB000252.

Ratschbacher, L., W. Frisch, G. Liu, and C. Chen (1994), Distributed deformation in southern and western Tibet during and after the India-Asia collision, J. Geophys. Res., 99, 19,917-19,945.

Regard, V., C. Faccenna, J. Martinod, O. Bellier, and J.-C. Thomas (2003), From subduction to collision: Control of deep processes on the evolution of convergent plate boundary, J. Geophys. Res., 108(B4), 2208, doi:10.1029/2002JB001943.

Richter, F. M., and D. P. McKenzie (1978), Mantle convection and the thermal structure of the planets, J. Geophys. Res., 83, 4485-4496.

Rowley, D. B. (1996), Age of initiation of collision between India and Asia: A review of stratigraphic data, Earth Planet Sci. Lett., 145, 1-13.

Searle, M. P., et al. (1987), The closing of Tethys and the tectonics of the Himalaya, Geol. Soc. Am. Bull., 98, 678-701.

Searle, M. P., R. R. Parrish, K. V. Hodges, M. W. Hurford, M. W. Ayres, and M. J. Whitehouse (1997), Shisha Pangma leucogranite, South 
Tibetan Himalaya: Field relations, geochemistry, age, origin, and emplacement, J. Geol., 105, $295-317$.

Sobouti, F., and J. Arkani-Hamed (2002), Thermomechanical modeling of subduction of continental lithosphere, Phys. Earth Planet. Inter., 131, 185 203

Stein, C. A., S. Cloetingh, and E. Wortel (1989), SEASAT-derived gravity constraints on stress and deformation in the northeastern Indian Ocean, Geophys. Res. Lett., 16, 823-826.

Toussaint, G., E. Burov, and L. Jolivet (2004), Continental plate collision: Unstable versus stable slab dynamics, Geology, 32(1), 33-36.

Turcotte, D. L., and G. Schubert (2002), Geodynamics, Cambridge Univ. Press, New York

van den Beukel, J., and R. Wortel (1987), Temperatures and shear stresses in the upper part of a subduction zone, Geophys. Res. Lett., 14, 1057-1060.
Vanderhaeghe, O., S. Medvedev, P. Fullsack, C. Beaumont, and R. A. Jamieson (2003), Evolution of orogenic wedges and continental plateaux: Insights from crustal thermal-mechanical models overlying subducting mantle lithosphere, Geophys. J. Int., 153, 27-51

Vermeer, P. A., and P. de Borst (1984), Non-associated plasticity for soils, concrete and rocks, Heron, 29(3), 1-75.

Watts, A. B., and E. Burov (2003), Lithospheri strenght and its relationship to the elastic and seismogenic layer thickness, Earth Planet. Sci. Lett. $213,113-131$.

Willet, S. (1999), Orogeny and topography, J. Geophys. Res., 104, 28,957-28,981.

Willet, S. D., and C. Beaumont (1994), Subduction of Asian lithospheric mantle beneath Tibet inferred from models of continental collision, Nature, 369 $642-645$.
Williams, C. A., C. Connors, F. A. Dalhen, E. J. Price, and J. Suppe (1994), The effect of brittle-ductile transition on the topography of compressive mountain belts on Earth and Venus, J. Geophys. Res., 99, $19,947-19,974$

Yin, A., T. M. Harrison, M. A. Murphy, M. Grove, S. Nie, F. J. Ryerson, W. X. Feng, and C. Z. Le (1999), Tertiary deformation history of southeastern and southwestern Tibet during the Indo-Asian collision, Geol. Soc. Am. Bull., 111, 1644-1664.

J.-P. Avouac, Geological and Planetary Sciences Division, California Institute of Technology, Mail Code 100-23, Pasadena, CA 91125, USA.

E. Burov and G. Toussaint, Laboratoire de Tectonique UMR7072, University of Pierre and Marie Curie, 4 Place Jussieu, F-7525 Paris, Cedex 05, France. (evgenii.burov@lgs.jussieu.fr) 